\title{
Strain localization in ductile rocks: a comparison of natural and simulated pinch-and-swell structures
}

\author{
Max Peters ${ }^{\mathrm{a}, *}$, Alfons Berger ${ }^{\mathrm{a}}$, Marco Herwegh $^{\mathrm{a}}$, Klaus Regenauer-Lieb ${ }^{\mathrm{b}}$ \\ ${ }^{a}$ Institute of Geological Sciences, University of Bern, Switzerland \\ ${ }^{b}$ School of Petroleum Engineering, University of New South Wales, Australia
}

\begin{abstract}
We study pinch-and-swell structures in order to uncover the onset of strain localization and the change of deformation mechanisms in layered ductile rocks. To this end, boudinaged monomineralic veins embedded in an ultramylonitic matrix are analyzed quantitatively. The swells are built up by relatively undeformed original calcite grains, showing twinning and minor subgrain rotation recrystallization (SGR). Combined with progressive formation of high-angle misorientations between grains, indicative of SGR, severe grain size reduction defines the transition to the pinches. Accordingly, dynamically recrystallized grains have a strong crystallographic preferred orientation (CPO). Towards the necks, further grain size reduction, increasingly random misorientations, nucleation of new grains and a loss of the $\mathrm{CPO}$ occur. We postulate that this microstructure marks the transition from dislocation to diffusion creep induced by strain localization. We confirm that the development of boudins is insensitive to original grain sizes and single-crystal orientations. In order to test these microstructural interpretations, a self-consistent numerical grain size evolution is implemented, based on thermo-mechanical principles, end-member flow laws and microphysical processes. Applying constant velocity and isothermal boundary conditions to a 3-layer finite element pure shear box, pinch-and-swell structures emerge out of the homogeneous layer through grain size softening at a critical state. Viscosity weakening due to elevated strain rates and dissipated heat from grain size reduction promotes strain rate weakening until a critical grain size is reached. At this point, a switch from dislocation to diffusion creep occurs. This state locks in at local steady states and is microstructurally expressed in pinches and swells, respectively. Thus, boudinage is
\end{abstract}

\footnotetext{
* Corresponding author

Email address: max.peters@geo.unibe.ch (Max Peters)

$U R L:$ http://www.earthsci.unibe.ch/tectonics/index.htm (Max Peters)
} 
identified as an energy attractor, identifying the high-energy steady state of an extending layered structure. We conclude from the similarity between natural observations and numerical results that critical deformation conditions of ductile creep can be derived for the surrounding highly-strained host rock matrix.

Keywords: Deformation mechanisms; Boudinage; Microstructural evolution; Thermal feedback; Numerical methods

\section{Introduction}

Boudinage and folding structures are frequently investigated in order to assess the rheology of a creeping material, its mechanical properties as well as the structural evolution. These localization patterns are classically approached either by the study of natural structures (e.g. Goscombe et al., 2004; Hudleston and Treagus, 2010), experimental work or numerical simulations. While classical experimental research has mainly focused on reproducing geometries and describing simplified rheologies (e.g. Abbassi and Mancktelow, 1992; Kidan and Cosgrove, 1996; Neurath and Smith, 1982; Paterson and Weiss, 1968; Ramberg, 1955), numerical simulations have increasingly been used in order to investigate the microphysical framework and the dynamic evolution of the investigated geological structure (e.g. Abe and Urai, 2012; Hobbs et al., 2007, 2008; Mancktelow, 2001; Mancktelow and Abbassi, 1992; Passchier and Druguet, 2002; Regenauer-Lieb et al., 2006; Schmalholz and Fletcher, 2011; Schmalholz and Schmid, 2012; Schmalholz et al., 2008). Direct comparisons between numerical simulations and natural boudinage structures have been the subject of renewed interest (Gardner et al., 2015; Peters et al., 2015; Schmalholz and Maeder, 2012), but a detailed analysis of the mechanics and physics of the phenomenon has not been performed to date. In this contribution, we intend to fill this gap. We present a working hypothesis based on field observations, which is subsequently investigated in depth using numerical methods. We identify and analyze the effects of complex rheological transitions and coupled microphysical relationships postulated in the foregoing analysis of natural microstructures.

The ductile class of boudinage, expressed by symmetric pinch-and-swell structures (drawn boudins in the nomenclature of Goscombe et al., 2004), has recently been interpreted as the result of visco-plastic deformation of a power-law layer (Schmalholz and Maeder, 2012; Schmalholz et al., 2008). In contrast, Gardner et al. (2015) have presented a combined Mohr-Coulomb strain 
localizing behavior linked with subsequent viscous creep for the initiation of pinch-and-swell structures. In the latter study, the inception of boudinage was controlled by an intrinsically unstable (brittle) material behavior, after which the material was allowed to creep in a ductile manner. In the ductile field, Schmalholz and Maeder (2012) implemented small-scale heterogeneities focussing strain and resulting in localization. The underlying localization criterion was provided by the study of Fletcher (1974), in which a linearized power-law material behavior was considered. The introduced heterogeneities are thought to stem from pre-existing structural perturbations, i.e. geometric interactions caused by structural, material and inherited rheological imperfections or a combination thereof. The application of such imperfections seems to be an appealing concept for geological applications, as their appearance can be justified from the heterogeneities or inherited structural patterns (anisotropy) of real materials (e.g. Mancktelow and Abbassi, 1992; Paterson and Weiss, 1968; Rybacki et al., 2014). Another advantage from a technical point of view is that small geometric perturbations of a numerical mesh are useful in order to avoid the mesh-sensitivity of numerical simulations, but their seed requires a robust analysis of the localization problem (Peters et al., 2015). The concept of pre-existing weaknesses has, however, recently been challenged by e.g. Hansen et al. (2012), who suggested that localized deformation appears irrespective of the presence of structural heterogeneities under a constant stress boundary condition. For constant strain rate boundary conditions, these authors postulated a critical imperfection size or strength to be met in order to trigger localization.

Localization phenomena can be discussed in further details when explicitly calculating the energy flows during deformation, thus allowing the assessment of complex feedback phenomena. To this end, an energy-based framework of localization has been proposed and applied to simple generic case studies (e.g. Hobbs et al., 2011, 2007, 2009; Regenauer-Lieb et al., 2006; Regenauer-Lieb and Yuen, 2003, 2004). In this energy framework, heterogeneities are a possible seed, but not a necessary condition for localization to appear. On the contrary, the coupling of the temperaturestress evolution to the mechanical properties of the material is of great interest. While a theoretical discussion of this concept is readily available in literature (ibid.), a direct application to natural localization structures has not been provided yet. Such a comparison would not only allow an assessment of whether the theory can be further applied than solely investigating the physics of localization. We therefore not only want to use the approach to shed light on the poorly understood driving mechanisms or the creep regime for the initiation of boudinage, but also try to predict a 
useful application to the field. We therefore strive at uncovering the onset of boudinage in a ductile material by means of a detailed microstructural analysis of natural pinch-and-swell structures and numerical analyses, posing the following questions:

(i) Based on a microstructural study, can we provide insights into the mechanisms driving the onset of boudinage? How do grain sizes, textures and deformation mechanisms progressively adjust during the different stages of deformation?

(ii) Can pinch-and-swell structures be described as a rheological instability? In other words, are geometric-material imperfections essential, or can we find evidence of localization from homogeneous state at the scale of observation?

(iii) What is the physical relationship between microstructure (grain size, texture, deformation mechanism), material properties (thermal-mechanical, grain size reduction and growth parameters) and the deformation conditions (stress, strain rate, temperature)?

(iv) Based on numerical simulations, can the microstructural evolution and the natural creep conditions during boudinage and of the surrounding host rock matrix be quantitatively assessed?

\section{Microstructural methods and sample description}

We studied various undeformed and low-grade boudinaged calcite veins embedded in an ultramylonitic matrix (host rock). Detailed microstructural studies of one representative sample shall be presented in the following. The specimen was cut parallel to the mineral lineation (L) and perpendicular to the foliation $\left(\mathrm{f}_{n}\right)$, prepared for a thin section of $30 \mu \mathrm{m}$ thickness, mechanically polished with a diamond paste and further chemo-mechanically polished with colloidal silica for electronbackscatter diffraction analysis (EBSD). High-resolution imaging and EBSD measurements were performed using a ZEISS Evo 50 scanning electron microscope, allowing crystal orientation mappings by means of EBSD (TSL/Ametek system). The setup was run under low-vacuum conditions (10 - $15 \mathrm{~Pa})$ at $15 \mathrm{nA}$ beam current and $20 \mathrm{kV}$ acceleration voltage. In order to resolve individual grains, the applied step sizes varied between 0.5 - $10 \mu \mathrm{m}$ for different study sites. Individual grain boundaries were found by means of the comparison of misorientation angles between neighboring points in the grain orientation map through the distinction between low-angle $\left(<15^{\circ}\right)$ to high-angle grain boundaries $\left(>15^{\circ}\right.$ ). A standard data clean-up procedure was performed (e.g. Rybacki et al., 
2014) by standardization of the confidence index (CI) of different points and subsequent neighbor CI correlation of 0.1 , removal of points with an CI $<0.1$ and one step of grain dilation, considering a minimum grain tolerance angle of $15^{\circ}$ for a minimum grain size of 5 correctly indexed points. Pole figure diagrams of grain orientations, presented as upper hemisphere, equal-area projections, using linear contouring for plots per point, are displayed in the vertical direction of finite strain $\left(\mathrm{f}_{n}\right)$ and parallel to the mineral lineation $(\mathrm{L})$. We further computed the fabric strength $(\mathrm{J})$ and maximum intensity $\left(\mathrm{I}_{\max }\right)$ of the textures. Finally, area-weighted mean recrystallized grain sizes $\left(\bar{d}_{\text {area }}\right)$ were calculated, as the grain size class of the largest grain fraction was found to dominate the bulk rheology of monomineralic aggregates (e.g. Berger et al., 2011; Herwegh, 2000; Shimizu, 2008).

Low-grade sedimentary nappes serve as excellent study areas for the investigation of the natural creep conditions of the uppermost ductile crust (e.g. Austin and Evans, 2007, 2009; Austin et al., 2008; Barnhoorn et al., 2004; Bestmann et al., 2000; Burkhard, 1990; Ebert et al., 2007a,b; Herwegh et al., 2005; Herwegh and Pfiffner, 2005; Renner et al., 2002). In such a setting, monomineralic veins are often formed synkinematically, while they are embedded in a creeping, high-strain matrix of the host rock. This setting allows us to determine creep conditions of these layers varying between the pre- to post-localized states, which can later be potentially upscaled for tectonic processes. For these reasons, we present a detailed microstructural investigation of boudinaged pure calcitic veins, sampled in the Doldenhorn nappe of the Helvetic Alps (Switzerland). The Doldenhorn nappe forms the central part of the nappe stack of the Helvetic Alps, overlying the Gastern granite as part of the external crystalline basement of the Central Swiss Alps (Herwegh and Pfiffner, 2005). For this study area, a rich dataset of the paleo-deformation conditions was assembled that describe the main episode of thrusting. The record comprises calcite-graphite thermometry on organic nano-flakes defining the foliation and calcite grains from ultramylonites (Herwegh and Pfiffner, 2005), estimations of deformation rates through the Paleowattmeter scaling relationship (Austin et al., 2008) and geodynamic constraints on Alpine orogeny (Burkhard, 1988; Herwegh et al., 2005). While the emplacement of the nappe potentially lasted ca. $10 \mathrm{Ma}$ (Herwegh et al., 2005), regional anchizonal to lower greenschist metamorphic conditions endured for around 2 - 5 Ma (Arkai et al., 2002). Herwegh and Pfiffner (2005) characterized the majority of deformation structures as highly localized thrust faults. For the deformed Quintnerkalk sample presented here, a minimum deformation temperature of ca. $350^{\circ} \mathrm{C}$ was obtained. Microstructures associated with retrograde shearing 
mostly appear as cataclasites, which significantly differ from those of the main ductile deformation event. Thus, we assume that temperature is isothermal at least at the scale of the hand specimen. Deformation rates, based on grain size calculations and the previously discussed deformation temperatures, were calculated at $10^{-12}<\dot{\epsilon}\left[\mathrm{s}^{-1}\right]<10^{-10}$ in the ultramylonites of the study area (Austin and Evans, 2009; Austin et al., 2008; Ebert et al., 2007a). High strain is accommodated by composite viscous creep via dominant dislocation creep joint by a minor component of diffusion creep in the calcite rich lithologies. Structural data from field relations have principally confirmed these deformation conditions (Ebert et al., 2007b).

\section{The microstructures of pinch-and-swell layers}

Undeformed veins and distinct grades of deformation are studied in monomineralic calcite veins in order to study the onset of localization, leading to the inception of boudinage (Figs. 1,2). We expect to observe severe variations between the early stages of deformation and highly localized necks in pinch-and-swell structures. In this study, the determination of the onset of strain localization, weakening processes and associated deformation mechanisms are examined during the development of pinch-and-swell structures from calcite veins. In a following section, we will concern with the surrounding polymineralic host rock matrix. Note that localization structures in which geometric interactions disturbed the stress field, e.g. boudinage of multi-layers (arrow in Fig. 2a), were systematically excluded from the current study. Here, microphysical processes that are not preconditioned by geometric influences or the interferences of geometry with the creep conditions are relevant. The influence of geometric perturbations has already been treated in the theoretical study of Needleman and Tvergaard (1992), in the experimental work of Kidan and Cosgrove (1996) and in numerical simulations by Schmalholz and Maeder (2012).

\subsection{Undeformed veins}

First-order characteristics of calcite veins can be studied in such rare layers showing no evidence of boudinage (Fig. 1a). The initial grain size of original calcite clasts ranges between ca. $250-1500 \mu \mathrm{m}$ and is broadly unimodal distributed. Idiomorphic coarse grains appear as pervasively and intensely overprinted by thick mechanical twins (twin boundary $>5 \mu \mathrm{m}$ ), resulting in the common sweeping undulose extinction of primary grains. Across such veins, a crystallographic preferred orientation $(\mathrm{CPO})$ cannot be detected. A common feature among these almost unmodified 
veins is brittle fracturing mostly along grain boundaries and the subsequent precipitation of calcite or dolomite, which is associated with deformation during retrograde shearing (Herwegh and Pfiffner, 2005). The interfaces between the polymineralic matrix of the host rock and the monomineralic calcite veins are frequently sharp and straight, although they sometimes appear slightly undulose (see Fig. 1a).

\subsection{Boudinaged veins}

The boudinaged calcite veins are identified as pinch-and-swell structures, i.e. the ductile class of boudinage, due to their characteristic symmetric shape of the boudins on the macroscopic scale. The pinch-and-swell layers indicate irregular spacings between the swells, which do not express a dominant (periodic) wavelength, as evidenced in Figure 2a. The average aspect ratio of the swells $w / l$ is around $0.47 \pm 0.10$, which is within the suggested range for drawn boudins (Goscombe et al., 2004). Individual grain sizes in these swells are similar to the undeformed veins, as described above. Most commonly, a single calcite host grain (e.g. Fig. 1b), or seldomly multiple coarse-grained calcite clasts form the swells (Fig. 2a). In general, the swells appear as intact or only slightly deformed calcite host grains, marked by pervasive twinning. Towards the grain boundaries, the twin spacing becomes narrower and twin planes bend towards the grain boundaries. The transition towards the pinches is marked by continuous grain size reduction of calcite, which becomes visible in the inverse pole figure (IPF) maps (e.g. Fig. 2c,d).

In the pinches, grain orientation mappings indicate that a range of different crystallographic orientations has been obtained, which are different from those of the individual host crystal orientations in the swells (Fig. 2c,d). This textural contrast can also be examined within fine calcite grains along former twin planes in host clasts or around them (arrow in Fig. 2b). We measured various single crystals of the swells and compared them to the orientations of the fine-grained fractions in the adjacent pinches. The data in Figure 3 have been gathered from single-point measurements and therefore single-crystal orientations do not concur on single points in the pole figure diagrams. While host calcite clasts reveal single-crystal orientations (e.g. Fig. 3b), the $[c]$-axis distributions studied in the fine-grained fractions in the pinches show strong clustering of $[c]$-axes at the periphery of the pole figures (Fig. 3b,c). The pole figure diagrams indicate spread point maxima, somewhat inclined to the host orientations and perpendicular to the $Y$-direction. $[a]$-axes are (sub-)horizontally aligned along a great circle in $X$-direction (Fig. 3a,b). Although the textu- 
ral strength of the measured fine-grained fractions is significantly lower than for the single-crystal hosts with maximum intensities, textural strengths imply that the obtained textures are distinct from being random $(\mathrm{J}>1)$. Crystal orientation distributions of all crystallographic planes are relatively broad. In comparison to other pinches, the same general texture irrespective of the host grain orientation was found. We additionally compared one raw $[c]$-axis pole figure and found that the fine-grained fraction has developed new orientations compared to its host (Fig. 3b). Moreover, the chemical variation of calcite across the pinch-and-swell structure studied in detail here was additionally analyzed by means of cathodoluminescence microscopy. Based on the same calcite luminescence of both pinch and swell, Figure 4 reveals the similarity in chemical composition of calcite between recrystallized fine-grained fractions and the coarser-grained adjacent host grain (thin dashed line).

In order to better assess whether these new orientations follow any systematic trend or fabric attractor, either relative to the host clast or along the pinch, we examined misorientation angles across one characteristic pinch-and-swell structure (Fig. 5). In the plot, misorientation angles associated with potential slip along twin planes of the host grain and misorientation angles at the transition of low- to high-angle grain boundaries are highlighted. The origin orientation was arbitrarily chosen in the center of the host grain in the swell, but in line with the bulk orientation of the host (point "B" in Fig. 2c). Tracing the profile within the swell, it is convenient to follow the profile line for point-to-origin misorientation angles (blue line). For measurements within the host clast, there appears to be no noticeable variation in misorientation angle (Fig. 5-i). As soon as areas of crystal orientations different from the host orientation occur, misorientation angles diverge from the orientation of the host by around $10-15^{\circ}$, which corroborates the transition to high-angle grain boundaries (Fig. 5-ii). This finding allows us to identify these areas as individual new grains that continuously developed from subgrains.

The boundary between the host grain forming the swell $\left(\bar{d}_{\text {area }}=1255 \mu \mathrm{m}\right.$, Fig. $\left.6 \mathrm{~b}\right)$ and the surrounding finer calcite grains coincides with progressively increasing misorientations and severe grain size reduction. While for the first few hundred micrometers (see Fig. 5-ii) this increase is still marked by high-angle boundaries (point-to-point), there exists no correlation to the initial orientation of the swell for the pinch anymore (point-to-origin). Therefore, changes by point-to-point measurements are traced from here on (red line). Across the pinch, huge jumps in misorientation angles of these grains indicate a loss of any systematic textural relation compared to both the original 
host and their direct neighbor grain orientations (Fig. 5-iii). In addition, grain sizes continuously decrease from $\bar{d}_{\text {area }}=56 \pm 13 \mu \mathrm{m}$ (Fig. 6c-ii) to $\bar{d}_{\text {area }}=21 \pm 6 \mu \mathrm{m}$ (Fig. 6c-iii), which correlates with the aforementioned change from the progressive formation of high-angle grain boundaries (ii) to a random texture (iii), observed in Figure 5, and the more diffuse CPO described earlier (Fig. $3 b)$. This gradient in grain size is confirmed by the apparently bimodal grain size distribution of grains in the pinch (Fig. 6c).

\subsection{Surrounding host rock matrix}

The surrounding polymineralic matrix is defined by a fine-grained ultramylonite, mainly consisting of calcite (ca. 30 area-\%), white mica, dolomite and nano-flakes of organic origin (see Fig. 1b). Both darkish bands of aligned graphite platelets, very thin pure calcite and disaggregated calcite veins determine the apparent foliation of the ultramylonitic matrix (Figs. 1b, 2a). On the microscale, this foliation is defined by continuously horizontally aligned calcite grains and secondary phases, mostly graphite and white mica, at calcite grain boundaries, described as a pinning microstructure. The IPF map reveals that calcite grains are largely dispersed with other matrix phases and separated by secondary particles (Fig. 2e). Calcite grains share lobate grain boundaries and their mean grain size is $\bar{d}_{\text {area }}=10 \pm 4 \mu \mathrm{m}$.

In some places, spatially correlated calcite grains are horizontally aligned and form coarsegrained aggregates, having mostly straight grain boundaries (arrow in Fig. 2). These have earlier been interpreted as remnants of calcite veins (Herwegh et al., 2005). For this reason, the texture of calcite in the matrix inherits a certain grain size dependency. Coarse-grained calcite aggregates are responsible for the weak, though noticeable clustering of characteristic slip directions in the pole figure diagrams. The bulk misorientation angle distribution appears closest to being correlated (Fig. 7). The highly dispersed, finest-grained fraction of calcite grains in the matrix is responsible for the evidently diffuse CPO (Fig. 3d). Due to the severe influence of secondary particles, the grain size distribution is right-skewed (Fig. 6d).

\section{Numerical implementation of natural microstructures}

\subsection{Elasto-visco-plastic finite element framework}

We applied the numerical implementation of the Paleowattmeter, defining the scaling relationship between grain size, strain rate, differential stress and temperature (Austin and Evans, 2007, 2009). 
The grain size evolution of calcite is balanced by the contributions of grain size reduction and grain growth and is dynamically evolving based on thermo-mechanical principles, end-member flow laws and microphysical processes, based on the approach of Herwegh et al. (2014). A coupled system of equations is solved, which combines the temperature and stress evolution of the elasto-viscoplastic system with the material properties through the stress equilibrium and the energy balance equations. Herwegh et al. (2014) have introduced two underlying feedbacks, namely the coupling between the equations of mass, momentum and continuity and a secondary one that arises from the relation between the evolution of grain size, temperature and the stored energy. From an energetic perspective and according to its unit, the scaling relationship of the Paleowattmeter is a measure of the energy dissipated as heat, which defines a "Joulemeter over a time increment", rather than being a measure of the total energy conversion with respect to a given length of time.

In the numerical scheme, each finite element represents a grain size distribution function of a population of grains (Fig. 8a). The deformation sequence initiates with elastic loading and transient creep in the strain hardening regime, followed by strain softening and the establishment of a viscous steady state (Fig. 8a). At this stage, a unique grain size distribution develops proportional to the rate of mechanical energy input. The rate of grain size change dynamically follows the enthalpy of grain growth (Herwegh et al., 2014). Peters et al. (2015) applied this numerical scheme for a single-layer setup and focussed on the structural evolution of pinch-and-swell structures due to grain size softening. In this framework, a random distribution of grain sizes is introduced across a central elasto-visco-plastic layer with a composite viscous rheology, combining calcite creep laws of grain size insensitive dislocation creep (Schmid et al., 1980) and grain size sensitive diffusion creep (Herwegh et al., 2003) as competing end-member flow laws. The layer is embedded in a weaker linear matrix. While grain sizes within the central layer can adapt to the physical conditions by means of grain size reduction or grain growth, respectively, the matrix grain size is kept constant as strain is accommodated by diffusion creep only. This precondition mechanically resembles the pinning microstructure of the surrounding high-strain matrix, in which calcite grain growth is inhibited by dispersed secondary particles at grain boundaries. We will later elaborate on the microstructural role of diffusion creep in the matrix. Here, we include the effects of thermal softening and extend the numerical analysis to appropriate deformations conditions, using an isothermal temperature $\left(T_{b}\right) 350^{\circ} \mathrm{C}$ and a constant strain rate $\left(\dot{\epsilon}_{0}\right)$ of $10^{-12} \mathrm{~s}^{-1}$ at the left and right box boundaries. The maximum grain size inside the central layer is capped to $1200 \mu \mathrm{m}$, which is close to the maximum 
grain size of calcite clasts in the natural swells (see Fig. 1a). By means of an additional sensitivity study we confirm that this maximum grain size is approximately the equilibrated value for the chosen boundary conditions. The applied thermo-mechanical properties of calcite are summarized in Table 1.

In order to assess the sensitivity of the structure to random material imperfections and to avoid meshing artefacts, we carried out a pre-loading perturbation step, using an eigenmode frequency analysis (Peters et al., 2015). This analysis is used to allow natural localization patterns to develop in the subsequent loading step. The perturbation step from the frequency analysis is designed to avoid unphysical localization patterns that develop on the inherent numerical grid wavelength, being solely triggered by round-off errors on grid nodes. By investigating all natural frequencies and wavelengths of a given structure, small perturbations can be induced on all these natural frequencies such that the localization pattern can evolve through a competition of the geometry of the natural structure and the applied boundary conditions and not the chosen mesh-discretization length scale. In the extensional case, the positive feedback between matrix response and natural frequencies of the central layer was shown to lead to localization patterns in form of pinch-and-swell structures at sites wherever matrix and layer eigenmodes meet and mutually enhance each other, forcing strain to localize along ductile shear bands (see fig. 9b of Peters et al., 2015).

\subsection{Mechanical and microstructural evolution}

For individual finite elements, the mechanical state of the system, described by the von Mises stress, plastic strain (rate), contribution of dislocation to the composite viscous creep, local temperature and grain size have been recorded against the normalized computational time $\left(t^{*}=t \times \dot{\epsilon}_{0}\right)$. The results for one characteristic pinch-and-swell structure are given in Figure 9, in which the endmembers of an individual swell (blue line) and a pinch (red line) are highlighted. Soon after transient loading, flow stresses $\left(\sigma_{\text {Mises }} \approx 151 \mathrm{MPa}\right.$, Fig. 9a) and mean grain sizes $(\bar{d} \approx 400 \mu \mathrm{m}$, Fig. 9b) converge to homogeneous values across the layer ((1) in Fig. 9a). This response emerges from the energy optimization of the scaling relationship of the Paleowattmeter. This viscous steady state is regarded as the natural response of the system to the ambient boundary conditions. At this stage, dislocation creep dominates the total creep of the layer by ca. $80 \%$ (Fig. 9c). The resulting effective viscosity contrast between layer and matrix is around 12 at this time of the simulation. Upon continued loading, plastic strain equally rises inside the layer until ca. $t^{*} \approx 10.2$ (Fig. 9d). 
This is the point in time when the mechanical evolution of the layer starts to diverge, leading to the inception of the pinch-and-swell structure $((2)$ in Fig. 9a). For this critical level of strain, bulk material softening is triggered, expressed by a switch from dislocation to entirely diffusion accommodated creep (Fig. 9c) and severe grain size reduction to ca. $185 \mu \mathrm{m}$ in the pinch. After localization has occurred, the evolving pinch has reached a peak stress of around $160 \mathrm{MPa}((2 \mathrm{a})$ in Fig. 9a) and grain sizes equilibrate to a characteristic unique grain size of ca. $380 \mu m$. Because the amount of strain inside the pinch is continuously increasing, associated with accelerated strain rates, while grain sizes are further decreasing, creep is accommodated via diffusion creep. Finally, due to decreasing strain rates ((3a) in Fig. 9a), expressed by a gentler slope in the evolution of the plastic strain (see Fig. 9d), the contribution of dislocation creep finally becomes dominant again. Stress and grain size data of the pinch reveal stable conditions towards the end of the simulation for a bulk extension of $100 \%$ ((4a) in Fig. 9a).

In contrast to the evolution of the pinch, the swell experiences stress relaxation $((2 \mathrm{~b})$ in Fig. 9a). Mean grain sizes quickly equilibrate to the maximum grain size of $1200 \mu \mathrm{m}$. Slow strain rates, associated with low stresses and no further accommodation of plastic strain favor dislocation dominated creep (a. 90\%) and ultimately grain growth in the swell ((3b) in Fig. 9a). At the end of the simulation, stable conditions are achieved in the swells ((4b) in Fig. 9a). The evolution of the plastic strain suggests that the swells are one strain-invariant, thus microstructurally stable, end-member once having reached steady-state conditions (Fig. 9d). This behavior is apparently insensitive to the chosen maximum grain size. Owing to the large distortions of the mesh by high strains, some numerical oscillations cannot be avoided. Important to note is that the greater part of these oscillations arises from the grain size evolution through the interplay between grain growth and grain size reduction. A decreasing amount of plastic strain and stress towards the stable swell describes a transient regime in the progressively developing pinch $((3 \mathrm{c})$ in Fig. 9a) between the stable end-member structures (for $t^{*}>32$ ). In total, the dynamic rheological evolution depicts the existence of more than one steady state (Fig. 9a), i.e. (1) an initial homogeneous state out of which localization emerges and the stable end-members. These are (4a) the pinch and (4b) the swell, respectively. We will therefore come back to the interpretation of multiple steady states in the following section. 


\section{Discussion: Linking the microstructural to the mechanical evolution of localization}

We have provided indications of the onset of strain localization and the structural development of layered ductile rocks, presented by detailed microstructural and numerical analyses of pinch-andswell structures. In doing so, we have attempted to resolve microstructural adjustments by means of dynamic recovery and hardening processes in space and time and compared those in analyses of infinitesimally small and bulk finite strain. In connection with this, we have established pinches and swells as microstructurally and mechanically stable end-members of the same structure. In the transition between theses end members, transient stages of deformation permit assessment of the microstructural evolution, once localization has occurred.

The inception of pinch-and-swell structures was found to be defined by the final energy attractor (steady state) of boudinage at the transition from dislocation to diffusion dominated creep. This inference was confirmed by a study of naturally boudinaged veins and numerically simulated layers. After localization has occurred, the pinch-and-swell structure becomes further amplified through continuous grain size reduction and an increasing contribution of diffusion creep in the pinches and growth in the swells at relatively high extensional strains during the numerical simulations (see Fig. 9). This strain softening behavior is characteristic for a visco-plastic material. Here, we are exclusively concerned with the ductile layer, whose rheology is driven by the interactions between its natural response to the boundary conditions. To this end, we have accessed pinch-andswell as a material bifurcation based on the preceding study of Peters et al. (2015). The study of naturally boudinaged layers (see e.g. Fig. 2a) has exposed that the trails of the veins appear as non-periodic structures. This pattern points towards a non-linear material behavior rather than a periodic solution of a linearized response. This is in contrast to the classical theory of wavelength selection of Biot $(1961,1964)$, for instance. In the current work, we have provided further evidence of the role of rheological instabilities that ultimately lead to complex localization patterns, which extends previous work on the onset of folding (e.g. Hobbs and Ord, 2012; Ord and Hobbs, 2013; Regenauer-Lieb et al., 2006). In the following, we will first establish the role of the matrix and then return to the deformation sequence of the layer in the following discussion.

\subsection{The role of the matrix}

In the current framework using isothermal boundary conditions, boudinage commences when material softening is activated by grain size sensitive viscous creep (Peters et al., 2015). For this 
reason, the matrix rheology was set to obey a linear diffusion creep response during the numerical experiments. The numerical setup is intended to mimic the strain-invariant ultramylonitic matrix, in which calcite veins have synkinematically been formed and boudinaged during continuous layer-parallel extension. Although we acknowledge that the numerical scheme is a simplification of a deformation behavior at the scale of an aggregate, the simulated matrix response resembles the initial conditions of the real host rock to a high degree for the following reasons. The natural polymineralic matrix is characterized by an extremely weak crystallographic preferred orientation of calcite grains (Fig. 3d). Furthermore, due to the pinning effects of secondary particles (see Fig. 1b), grain growth is efficiently prohibited and the matrix grain size is kept relatively fine (Fig. 6d).

Based on these findings, the matrix rheology is associated with grain boundary sliding processes, which are typically accommodated by diffusion creep (e.g. Fliervoet and White, 1995; Fliervoet et al., 1997; Herwegh et al., 2003; Krabbendam et al., 2003). Such a diffusion creep matrix is thought to reflect mechanical and microstructural steady-state conditions (e.g. Herwegh et al., 2005, 2011; Krabbendam et al., 2003) for the suggested high-strain environment of the ultramylonitic host rocks of the study area (Austin et al., 2008; Herwegh and Pfiffner, 2005). This bulk behavior has been altered by the presence of disintegrated calcite aggregates only marginally (Figs. 2e, 7), as evidenced by some type of correlation in misorientation angles and a non-random texture (Figs. 3d, 7). At these spatially rather limited sites, dislocation creep accommodated grain boundary sliding was probably enhanced.

\subsection{Evolution of the swells: a stable end-member?}

In the natural sample, the most prominent feature of the swells is pervasive mechanical twinning (most likely on $e\{10 \overline{1} 4\}$ ), which is commonly associated with strain hardening under lowtemperature deformation conditions of the host grains (e.g. Barnhoorn et al., 2004; de Bresser and Spiers, 1997; Rybacki et al., 2013). A majority of the twins appears as type-II twins (according to Burkhard, 1993). Towards the grain boundaries, twin planes were found to bent (type-III twins), indicating dislocation glide (Fig. 2d). This microtexture is characteristic of dislocation creep regime 1 of Hirth and Tullis (1992). We therefore derive a certain amount of strain-controlling, transient creep in the swells. Herwegh and Pfiffner (2005) referred to a second stage of transient deformation, manifest in subgrain rotation recrystallization (SGR) and microshearing along pre-existing twin planes or grain boundaries (e.g. arrow in Fig. 2b). Crystal-lattice misorientations progres- 
sively increase towards the host grain boundaries (Fig. 5-i) until new grains are formed by means of dynamic recrystallization (SGR). This microstructure resembles a core-mantle structure and implies a change to dislocation climb accommodated dislocation creep. Such a microstructure is characteristic of regime 2 of Hirth and Tullis (1992). Interestingly, progressive SGR proceeds over a few hundred micrometers into the pinches. It is related to severe grain size reduction along this gradient (Fig. 6c). The microstructure at the transition from pinches to swells basically resembles isolated porphyroclasts surrounded by dynamically recrystallized grains (Bestmann et al., 2006).

While the strain-hardening behavior of the host grain dominates the bulk rheology of the swell, the amount of softening through dynamic recrystallization (SGR) is clearly minor. This subordinate amount of transient creep could not achieve dynamic recovery of the swells, considering the large amount of twinning and their preserved original crystal-lattice orientations.

The crystallographic orientation of the swells is inherited from the primary crystallization of calcite into the vein (compare Fig. 3b,c). Thus, crystallization must have been driven by rapid growth kinetics (Higgins, 2006, and references therein), leaving no time to dynamically adjust to a fabric attractor. At the scale of individual grains, the swells are therefore stable microstructures with respect to time and the amount of accommodated strain. For this reason, we describe the swells as one steady-state end member of the boudinaged veins, because the conditions for localization with respect to boudinage were not met. Counterintuitively, the absence of an CPO aligned to the direction of shearing supports this assumption. Both mechanically and microstructurally stable, steady-state conditions are therefore attributed to the swells. The discovered strong CPO of the swell host grains suggests that this preserved anisotropy could have added to the localization pattern somehow (see Fig. 2a). A detailed examination of the influences of anisotropic elasticity (e.g. Bigoni and Loret, 1999; Bigoni et al., 2000) or the effect of initial clast (or twin) orientation on the critical resolved shear stress (Rybacki et al., 2013, and references therein) on the onset of localization, for instance, is clearly beyond the scope of this work. However, remnant calcite host grains exhibit distinct CPOs (compare Fig. 3b-c), limiting the strength of an inherited anisotropy in terms of mechanical stiffness.

\subsection{Evolution of the pinches: from transient creep to steady-state conditions?}

Dislocation creep mechanisms did not alter the swells significantly, albeit these processes have a much more pronounced effect during continuous necking. In the thin section, the rims of the swells 
have earlier been identified as core-mantle structures (Fig. 2c) that are found to be completely dynamically recrystallized eventually (Fig. 2d). This is regarded as the transient regime of ductile deformation that describes the continuous transition to the pinches. Because dynamic recovery processes were fast enough to adjust to ambient deformation conditions, calcite grains in the pinches are mostly twin-free and lack undulose extinction (see Figs. 1b, 2d). The misorientation angle profile of Figure 5-ii indicates dynamic recrystallization by means of progressive SGR, joint by severe grain size reduction (ii-iii in Fig. 6c).

When comparing the original crystallographic orientations of the host with those of the finegrained recrystallized grains in the swells, recrystallized pinches exhibit an CPO that is different from those of the host grains (Fig. 3b-c), although some single-crystal orientations seem to be aligned in a favoured orientation to the shear direction (Fig. 3a,b). However, Figure 3c demonstrates that the newly formed texture of the pinches evolves as a dynamic pattern. For all studied pinches, slip along $\langle c\rangle$ on $(a)$ can be identified. In comparison to the host orientation, the fabric shows a minor amount of rotation normal to $\langle c\rangle$ on the rhomb planes $(r)$ into a perpendicular orientation to the shear plane, favoring slip on $(a)$ (see Fig. 3b). We admit that strain partitioning alters a texture potentially (Kilian et al., 2011) and that an CPO evolution requires a sufficiently long duration and amount of strain during transient creep before developing into a steady-state fabric (Boneh et al., 2015; Herwegh and Handy, 1996; Pieri et al., 2001). As the CPO is broader than comparable samples from ductile shear zones (e.g. Austin et al., 2008; Barnhoorn et al., 2004; Bestmann et al. 2000) and the grain size distribution was found to be bimodal (Fig. 6c), steady-state conditions cannot be derived for the transitional zone in the pinch. Nevertheless, it becomes clear that the observed microfabrics were formed in a dynamic framework by means of dominant dislocation creep.

To this end, the numerical evolution has provided detailed insight into the transient regime, expressed by the deformation gradient between the stable end-members (see Fig. 9d). In this domain, strain rates and thus the amount of mechanical dissipation (shear heating) significantly differ. These differences, in turn, result in variations in mean grain sizes and, most importantly, in the rates of grain size change along the pinch. This behavior reflects the Paleowattmeter relationship (Austin and Evans, 2007, 2009; Herwegh et al., 2014). Consequently, whether grains tend to grow, or to reduce their size, respectively, is a function of the gradient of the rate of energy input locally along the pinch. While in the outermost sections, the pinch experiences relaxation, strain propagates to the center of the pinch causing further grain size reduction until stable conditions are achieved. 
We refer to this as the steady state of the pinch ((4a) in Fig. 9a). As the swells also reveal steadystate conditions, although at a different energetic level ((4b) in Fig. 9a), the end-members of the pinch-and-swell structure are locally stable. Note further that localization clearly emerges from homogenous conditions in the central layer ((2) in Fig. 9a). Hence, the evolution depicts multiple steady states with respect to time and location.

The sites of necking, expressing the areas that have accommodated the largest amount of extension, are associated with a randomization of misorientation angles (Fig. 5-iii). Moreover, the pole figure indicates a "smearing-out" by a decreasing strength of the former CPO, having no textural relation to the recrystallized grains at the rims (see raw $[c]$-axis plots in Fig. 3b). These grains presumably originate from the nucleation of new grains. This implies that either dynamic recovery by progressive SGR was not capable of adapting to elevated deformation rates in the pinches, or that the aggregates developed a critical minimum grain size, or a combination of thereof, triggering grain size sensitive creep. We attribute this behavior to diffusion creep accommodated grain boundary sliding, which is in line with former studies (e.g. Bestmann and Prior, 2003; Bestmann et al., 2006; Wightman et al., 2006). In a previous study of pinch-and-swell microstructures (Schmalholz and Maeder, 2012), severely reduced grain sizes and the absence of internal deformation patterns, such as twinning, undulose extinction or subgrains, were taken as proxies for grain boundary sliding accommodated by diffusion creep. We have provided additional textural evidence of the activation of diffusion creep in the necks of the boudinaged veins. Consequently, the following questions arise: does a diffusion creep microstructure reflect steady-state conditions and how does it from?

Common assumptions for microstructural steady state at high-strains comprise the development of (1) a unique mean grain size (e.g. Austin and Evans, 2007, 2009; Christie and Ord, 1980; Herwegh et al., 2014; Mercier et al., 1977; Michibayashi, 1993), associated with (2) a deformation regime at the boundary dislocation to diffusion creep (e.g. de Bresser et al., 2001, 1998; Shimizu, 2008), (3) a strain-invariant texture (e.g. Barnhoorn et al., 2004; Boneh et al., 2015; Hansen et al., 2014; Herwegh and Handy, 1996, 1998; Means, 1981), aside (4) the identification of mechanical steady state from experimental constraints (e.g. Heilbronner and Tullis, 2006; Hirth and Tullis, 1992). Furthermore, we have found evidence in natural examples. Regarding the study area, various studies indicate that dynamically recrystallized calcite in both surrounding matrix and veins have evolved towards the same steady-state grain size (attractor), taking the suggested high shear strains of the Doldenhorn nappe into account (Ebert et al., 2007a; Herwegh et al., 2005; Schmalholz and 
Maeder, 2012). These grain size data are compiled in Figure 10. The deformation temperature associated with the ductile deformation period has been calculated to $T \approx 350^{\circ} \mathrm{C}$. Mean grain sizes in both the ultramylonitic matrix and the dynamically recrystallized pinches clearly fall within the measured range of grain sizes in the highest-strained parts, for which steady-state conditions have been obtained. Whether or not this steady-state assumption is physically reasonable with respect to the microstructural evolution shall be discussed in the following section.

\subsection{The onset of localized deformation and the conditions of ductile creep}

Based on the first-order characteristics of the undeformed calcite layers, i.e. their initial grain size and crystallographic orientation, the anisotropy of the precursor material could not be ascribed to focus strain in the studied samples. At the microscopic scale, or, alternatively, with respect to the aforementioned microstructural characteristics, the layer can indeed be described as initially homogeneous. However, the list of potential candidates forming pre-existing heterogeneities is rather long, comprising any type of chemical impurity or structural inheritance, such as grains of different mineralogy or undulations of the vein - matrix interface. A more detailed assessment of potential driving forces for necking can be found in the work of Barnhoorn et al. (2005). Instead of opening a pointless discussion about the strength of these likely undetected perturbations here, we stress that at the scale of crystal-plastic processes $(\mu \mathrm{m}-\mathrm{mm})$, the onset of localized deformation is found to be insensitive to a heterogeneity of grain size, orientation or mineralogy. Although this finding does not exclude an intrinsically unstable material behavior per se, there are clear indications of visco-plastic processes initiating the development of pinch-and-swell structures. Consequently, the studied structure can be treated as a ductile instability. At this stage, we cannot directly infer the structural evolution from the natural microstructures and a direct comparison with the numerical results is extremely fruitful.

Transiting dislocation glide to climb progressively (dislocation creep regimes 1 - 2 of Hirth and Tullis, 1992), is related to continuous grain size reduction in the pinches (see Fig. 2c). Under constant temperature conditions, this gradient correlates to accelerated strain rates along the pinches. Continuous grain size reduction via progressive dislocation climb has consequently contributed to severe strain rate softening of the calcite veins. Necking has been observed to simultaneously occur with the switch from dislocation to diffusion dominated viscous creep, which was previously found at the transition from homogeneous (pure shear) to localized deformation (e.g. Austin and Evans, 
2009; Barnhoorn et al., 2005; de Bresser et al., 2001; Drury, 2005; Gueydan et al., 2014). For the numerical evolution in Figure 9 appropriate boundary conditions similar to natural constraints were applied. The numerical grain size evolution has revealed that initial grain sizes in the layer are far from being at steady state (Fig. 9b). They thus quickly equilibrate to a first viscous steady state ( $t^{*}$ $<10.2$, Fig. 9). For continued loading of the numerical box, the localization criterion is met, from where on flow stresses and grain sizes diverge from each of their equilibrated states. Interestingly, localization arises out of steady-state conditions. Note that a constant velocity boundary condition was used. This means that with increasing layer-parallel extension and continuous necking, the simulated system is subjected to continuously increasing mechanical dissipation in form of energy dissipated as heat from grain size reduction and thus enters the regime of plastic localization at this bifurcation point. Grain size reduction operates in the dislocation creep dominated regime, until a minimum grain size is reached $\left(t^{*} \approx 15\right.$, Fig. 9). In the following, material softening is in response to an increasing contribution of grain size sensitive diffusion creep, which has a strain rate weakening effect and ultimately induces continuous necking of the visco-plastic layer. In contrast, low strain rates and low stresses in the swells favor dislocation creep. As soon as both end members reach critical grain sizes, the boudinaged layer establishes mechanically and microstructurally stable conditions at two different levels. These conditions are expressed by spatially different steady states in the pinches and the swells, respectively. It is important to realize that the amount of dissipated heat from grain size reduction is capped by the presence of grain growth, operating as an endothermic process. The implementation of this energy sink into the grain size evolution has previously been suggested by numerous studies (e.g. Austin and Evans, 2007, 2009; de Bresser et al., 2001, 1998; Herwegh et al., 2005), and its relevance for the application of simulated rheologies on natural structures has been documented here.

Finally, we compare all grain size data with the mechanical dissipation obtained from the Paleowattmeter scaling relationship (contour lines in Fig. 10), following the original claim to apply pinch-and-swell structures as a deformation gage. For sake of simplicity, we assume perfect conversion of mechanical work into heat, for which the entire amount of mechanical dissipation is available for shear heating $(\lambda \rightarrow 0$ in the Paleowattmeter expression of Austin and Evans, 2007, 2009). While the simulated matrix grain size $(\bar{d}=10 \mu \mathrm{m}, " \mathrm{~m}$ " in Fig. 10) reflects the high-strain environment of the study area $\left(\dot{\epsilon} \sigma \approx 10^{-7}\left[\mathrm{MPa} \times \mathrm{s}^{-1}\right]\right)$, the simulated swell ("s" in Fig. 10) expresses the conditions of background deformation $\left(\dot{\epsilon} \sigma<10^{-16}\left[\mathrm{MPa} \times \mathrm{s}^{-1}\right]\right)$. These conditions limited the 
amount of deformation in the swells and are likely to be expressed by strain hardening in the natural sample. The comparison between measured grain sizes of the natural pinches and those of the simulated and natural matrix illustrates that conditions accurately reflect steady-state conditions, as suggested earlier. Moreover, the simulated data imply severe grain size reduction due to an increase in plastic work $(\dot{\epsilon} \sigma)$ through energy dissipation from grain size reduction (arrow in Fig. 10). As to the natural grain size measurements, the comparison therefore reveals that pinch-and-swell structures are appropriate deformation gages, as soon as mechanical and microstructural steady states have been identified. For such a stable end-member problem, a combined approach using numerical simulations paired with the study of natural microstructures delivers the ambient state of stress or strain rate, depending on the assumed boundary conditions. However, attention has to be paid when deriving the amount of total strain of the sample, as pinch-and-swell structures were found to inherit a significant difference between the inferred amount of extension of the boudinaged layer and the amount of bulk extension (e.g. Dabrowski and Grasemann, 2014; Mandal et al., 2007).

Despite the fact that the relative grain size trend from the simulated swell to pinch correlates very well with the trend found in the natural microstructure, one drawback of the current numerical setup is that it could not exactly reproduce the mean grain size of the pinches ("p" in Fig. 10). The measured mean recrystallized grain size in the pinch $\left(\bar{d}_{\text {area }}=21 \mu \mathrm{m}\right.$, Fig. $\left.6 \mathrm{c}\right)$ has been shown to fall into the diffusion creep dominated regime, which can also be inferred from calcite deformation mechanism maps (e.g. fig. 1a of Austin and Evans, 2009). Modifying the Paleowattmeter relationship for grain size sensitive creep in Figure 10, which was originally calculated for dislocation creep dominated conditions, could not reproduce the measured grain size. This finding points to more fundamental complications. In previous studies, the presence of grain growth, inducing strain hardening of the sample, was found to significantly inhibit further weakening (e.g. de Bresser et al., 2001). Grain growth processes can therefore exceed the amount of strain rate weakening through diffusion creep and even arrest localized deformation. On account of the high uncertainty on natural Arrhenius dependencies for both creep and growth laws, particularly the pre-exponential factor and activation energy, there is a sensitivity of the simulated rheological evolution to the rate of grain size adjustments and the resulting values in the pinch (Fig. 9b). Berger and Herwegh (2003) have shown that for a chosen value of the activation energy of grain growth, the resulting standard deviation on the mean grain size is severe [see their Tab. 4]. In order to accommodate further weakening of the pinches, additional processes such as dissolution-precipitation creep operating at 
slow deformation rates have to be incorporated as an alternative to grain size reduction by means of dynamic recrystallization in the post-localization regime. Alternatively, the kinetics of grain size adjustments require better constraints by means of field-based approaches in future studies.

Proceeding on the assumption that dislocation creep processes are optimizing the internal energy of a microstructure (Hobbs et al., 2011; Ord and Hobbs, 2011), the layer has developed multiple steady states. The transient regime shows that the gradient from swell to pinch attains different levels of dissipated energy. The energetic state either drives progressive grain size reduction, resulting in a positive feedback between grain size reduction and local heat supply, or causes grain growth in the outermost position of the pinches that experience relaxation.

The most progress in the current numerical scheme is made by the numerical implementation of deformational work that is translated into microstructure. This approach allows tracing a full grain size evolution involving transient, steady-state and localized deformation. In the numerical framework, we have directly applied flow laws and grain growth parameters of calcite that were obtained from laboratory experiments without adjusting parameters for numerical purposes. Furthermore, we have extended the applicability of the flow laws to the transient and localized regimes for realistic deformation conditions and embedded them in a self-consistent mechanical and microstructural evolution, which is based on thermo-mechanical principles and microphysical processes, i.e grain size reduction and grain growth.

\section{Concluding remarks}

We have introduced pinch-and-swell structures as a "role model" example for the interaction of strain localization and a switch in deformation mechanisms in layered ductile rocks. For a combination of critical deformation conditions and material properties, we found that the switch from grain size insensitive dislocation creep to grain size sensitive diffusion creep relates to strain rate weakening, induced by dissipated heat from grain size reduction along the extending layer. We infer that this behavior depicts a profound ductile instability. A combined study of the first-order deformation processes has exposed the great similarity between naturally boudinaged microstructures and theoretical predictions.

The current model is perfectly setup to implicate further microstructural complexities, such as an CPO-dependent grain size evolution, grain size sensitive dislocation creep (e.g. Renner and Evans, 2002) or mechanisms operating at extremely slow deformation rates, e.g. dissolution-precipitation 
creep contributing to viscous granular flow. The simulated rheological sequence has uncovered the existence of multiple steady states. These stable conditions are microstructurally and mechanically expressed in pinches and swells locally. While the concept of multiple steady states seems to be a somewhat unconventional concept to describe geological phenomena, it is a well established theory in the related discipline of non-linear geomechanics (e.g. Poulet et al., 2014; Veveakis et al., 2010; Yuen et al., 1978; Yuen and Schubert, 1979) that has to be placed in a geological context in the future. We have further provided indications of transient conditions between these stable end members, considering the equivalent rates of both dislocation and diffusion creep. For these reasons, the stable end members of boudinaged layers can now be approached in terms of a critical energy attractor, which allows for the identification of the high-energy steady state of an extending layered composite structure.

The studied pinch-and-swell microstructures appear non-periodic. Hence, the non-linear material response was approached by means of the energy theory of localization for elasto-visco-plastic materials (e.g. Hobbs and Ord, 2012; Hobbs et al., 2008; Regenauer-Lieb and Yuen, 2004). Since localization arises out of homogeneous conditions, we are able to derive the natural response of the deforming material and focus on the underlying microphysical processes. As a great advantage of the present numerical approach, next to the direct implementation of grain sizes and their evolution, is that laboratory-derived flow laws can directly be applied and extrapolated to natural conditions. One interesting finding of the numerical study is that layer and matrix reflect deformation at steady-state conditions (Fig. 9), which has earlier been hypothesized on a microstructural basis (e.g. Austin and Evans, 2007; Herwegh and Pfiffner, 2005). The difference between layer and matrix is that deformation of the latter is controlled by the yet undetermined creep behavior of a secondary-phase rich lithology. Such a structure is commonly associated with polymineralic, fine-grained ductile shear zones (e.g. Fusseis et al., 2006; Herwegh et al., 2011; White et al., 1980). Therefore, once constant physical conditions in both layer and surrounding matrix are identified, it is straightforward to obtain insights into the flow conditions of such rocks. Pinch-and-swell structures are thus ideal natural strain rate gages for the calculation of paleo-deformation conditions of high-strain zones. 


\section{Acknowledgements}

M. Peters and M. Herwegh acknowledge financial support from the Swiss National Fund by grant No. 200021-144381/1. K. Regenauer-Lieb was supported by the Australian Research Council (ARC Discovery grant No. DP140103015) and a collaboration agreement between UNSW and CSIRO.

The authors would like to thank their colleagues A. Karrech (University of Western Australia) and T. Poulet (CSIRO Energy and Resources Group, North Ryde) for their contributions to the numerical scheme. The authors finally thank S. Schmalholz (University of Lausanne) and B.E. Hobbs (The University of Western Australia) for fruitful discussions. This manuscript has profited from the comments of two anonymous reviewers. 


\section{References}

Abbassi, M.R., Mancktelow, N.S., 1992. Single layer buckle folding in non-linear materials - 1. Experimental study of fold development from an isolated initial perturbation. Journal of Structural Geology 14, 85-104. doi:10.1016/0191-8141(92)90147-0.

Abe, S., Urai, J.L., 2012. Discrete element modeling of boudinage: insights on rock rheology, matrix flow, and evolution of geometry. Journal of Geophysical Research 117. doi:10.1029/ 2011 JB008555.

Arkai, P., Ferreiro-Mählmann, R., Suchy, V., Balogh, K., Sykorova, I., Frey, M., 2002. Possible effects of tectonic shear strain on phyllosilicates: a case study from the Kandersteg area, Helvetic domain, Central Alps, Switzerland. Schweizerische Mineralogische und Petrographische Mitteilungen 82, 273-290. doi:10.5169/seals-62365.

Austin, N., Evans, B., 2007. Paleowattmeters: a scaling relation for dynamically recrystallized grain size. Geology 35, 343-346. doi:10.1130/G23244A.1.

Austin, N., Evans, B., 2009. The kinetics of microstructural evolution during deformation of calcite. Journal of Geophysical Research 114. doi:10.1029/2008JB006138.

Austin, N., Evans, B., Herwegh, M., Ebert, A., 2008. Strain localization in the Morcles nappe (Helvetic Alps, Switzerland). Swiss Journal of Geosciences 101, 341-360. doi:10.1007/ s00015-008-1264-2.

Barnhoorn, A., Bystricky, M., Burlini, L., Kunze, K., 2004. The role of recrystallisation on the deformation behaviour of calcite rocks: large strain torsion experiments on Carrara marble. Journal of Structural Geology 26, 885-903. doi:10.1016/j.jsg.2003.11.024.

Barnhoorn, A., Bystricky, M., Kunze, K., Burlini, L., Burg, J.P., 2005. Strain localization in bimineralic rocks: experimental deformation of synthetic calcite-anhydrite aggregates. Earth and Planetary Science Letters 240, 748-763. doi:10.1016/j.epsl.2005.09.014.

Berger, A., Herwegh, M., 2003. Differences in grain growth of calcite: a field-based modeling approach. Contributions to Mineralogy and Petrology 145, 600-611. doi:10.1007/ s00410-003-0473-y. 
Berger, A., Herwegh, M., Schwarz, J.O., Putlitz, B., 2011. Quantitative analysis of crystal/grain sizes and their distributions in 2D and 3D. Journal of Structural Geology 33, 1751-1763. doi:10. $1016 / j \cdot j$.jg. 2011.07 .002

Bestmann, M., Kunze, K., Matthews, A., 2000. Evolution of a calcite marble shear zone complex on Thassos Island, Greece: microstructural and textural fabrics and their kinematic significance. Journal of Structural Geology 22, 1789-1807. doi:10.1016/S0191-8141(00)00112-7.

Bestmann, M., Prior, D.J., 2003. Intragranular dynamic recrystallization in naturally deformed calcite marble: diffusion accommodated grain boundary sliding as a result of subgrain rotation recrystallization. Journal of Structural Geology 25, 1597-1613. doi:10.1016/S0191-8141(03) 00006-3.

Bestmann, M., Prior, D.J., Grasemann, B., 2006. Characterisation of deformation and flow mechanics around porphyroclasts in a calcite marble ultramylonite by means of EBSD analysis. Tectonophysics 413, 185-200. doi:10.1016/j.tecto.2005.10.044.

Bigoni, D., Loret, B., 1999. Effects of elastic anisotropy on strain localization and flutter instability in plastic solids. Journal of the Mechanics and Physics of Solids 47, 1409-1436. doi:10.1016/ S0022-5096 (98) 00119-7.

Bigoni, D., Loret, B., Radi, E., 2000. Localization of deformation in plane elastic-plastic solids with anisotropic elasticity. Journal of the Mechanics and Physics of Solids 48, 1441-1466. doi:10. 1016/S0022-5096(99)00095-2.

Biot, M.A., 1961. Theory of folding of stratified viscoelastic media and its implications in tectonics and orogenesis. Geological Society of America Bulletin 72, 1595-1632. doi:10.1130/ 0016-7606 (1961) 72 [1595:TOFOSV] 2.0.CO;2.

Biot, M.A., 1964. Theory of internal buckling of a confined multilayered structure. Geological Society of America Bulletin 75, 563-568. doi:10.1130/0016-7606(1964)75[563:TOIBOA]2.0. $\mathrm{CO} ; 2$.

Boneh, Y., Morales, L.F.G., Kaminski, E., Skemer, P., 2015. Modeling olivine CPO evolution with complex deformation histories: implications for the interpretation of seismic anisotropy in the mantle. Geochemistry, Geophysics, Geosystems 16, 3436-3455. doi:10.1002/2015GC005964. 
de Bresser, J.H.P., ter Heege, J.H., Spiers, C.J., 2001. Grain size reduction by dynamic recrystallization: can it result in major rheological weakening? International Journal of Earth Sciences 90, 28-45. doi:10.1007/s005310000149.

de Bresser, J.H.P., Peach, C., Reijs, J., Spiers, C.J., 1998. On dynamic recrystallization during solid state flow: effects of stress and temperature. Geophysical Research Letters 25, 3457-3460. doi:10.1029/98GL02690.

de Bresser, J.H.P., Spiers, C.J., 1997. Strength characteristics of the r, f, and c slip systems in calcite. Tectonophysics 272, 1-23. doi:10.1016/S0040-1951(96)00273-9.

Burkhard, M., 1988. L'Helvétique de la bordure occidentale du massif de l'Aar (évolution tectonique et métamorphique). Eclogae Geologicae Helvetiae 81, 63-114. doi:10.5169/seals-166171.

Burkhard, M., 1990. Ductile deformation mechanisms in micritic limestones naturally deformed at low temperatures $\left(150-350^{\circ} \mathrm{C}\right)$. Geological Society of London Special Publications 54, 241-257. doi:10.1144/GSL.SP.1990.054.01.23.

Burkhard, M., 1993. Calcite twins, their geometry, appearance and significance as stress-strain markers and indicators of tectonic regimes: a review. Journal of Structural Geology 15, 351-368. doi:10.1016/0191-8141(93)90132-T.

Christie, J., Ord, A., 1980. Flow stress from microstructures of mylonites: example and current assessment. Journal of Geophysical Research 85, 6253-6262. doi:10.1029/JB085iB11p06253.

Dabrowski, M., Grasemann, B., 2014. Domino boudinage under layer-parallel simple shear. Journal of Structural Geology 68, 58-65. doi:10.1016/j.jsg.2014.09.006.

Drury, M., 2005. Dynamic recrystallization and strain softening of olivine aggregates in the laboratory and the lithosphere. Geological Society of London Special Publications 243, 143-158. doi:10.1144/GSL.SP.2005.243.01.11.

Ebert, A., Herwegh, M., Evans, B., Pfiffner, O.A., Austin, N., Vennemann, T., 2007a. Microfabrics in carbonate mylonites along a large-scale shear zone (Helvetic Alps). Tectonophysics 444, 1-26. doi:10.1016/j.tecto.2007.07.004. 
Ebert, A., Herwegh, M., Pfiffner, A.O., 2007b. Cooling induced strain localization in carbonate mylonites within a large-scale shear zone (Glarus thrust, Switzerland). Journal of Structural Geology 29, 1164-1184. doi:10.1016/j.jsg.2007.03.007.

Fletcher, R.C., 1974. Wavelength selection in the folding of a single layer with power-law rheology. American Journal of Science 274, 1029-1043. doi:10.2475/ajs.274.9.1029.

Fliervoet, T.F., White, S.H., 1995. Quartz deformation in a very fine grained quartzo-feldspathic mylonite: a lack of evidence for dominant grain boundary sliding deformation. Journal of Structural Geology 17, 1095-1109. doi:10.1016/0191-8141(95)00007-Z.

Fliervoet, T.F., White, S.H., Drury, M.R., 1997. Evidence for dominant grain-boundary sliding deformation in greenschist- and amphibolite-grade polymineralic ultramylonites from the Redbank Deformed Zone, Central Australia. Journal of Structural Geology 19, 1595-1520. doi:10.1016/S0191-8141(97)00076-X.

Fusseis, F., Handy, M.R., Schrank, C., 2006. Networking of shear zones at the brittle-to-viscous transition (Cap de Creus, NE Spain). Journal of Structural Geology 28, 1228-1243. doi:10.1016/ $j \cdot j \operatorname{sg} .2006 .03 .022$.

Gardner, R.L., Piazolo, S., Daczko, N.R., 2015. Pinch and swell structures: evidence for strain localisation by brittle-viscous behaviour in the middle crust. Solid Earth 6, 1045-1061. doi:10. $5194 / \mathrm{se}-6-1045-2015$.

Goscombe, B.D., Passchier, C.W., Hand, M., 2004. Boudinage classification: end-member boudin types and modified boudin structures. Journal of Structural Geology 26, 739-763. doi:10.1016/ j.jsg.2003.08.015.

Gueydan, F., Précigout, J., Montési, L.G.J., 2014. Strain weakening enables continental plate tectonics. Tectonophysics 631, 189-196. doi:10.1016/j.tecto.2014.02.005.

Hansen, L.N., Zhao, Y.H., Zimmermann, M.E., Kohlstedt, D.L., 2014. Protracted fabric evolution in olivine: implications for the relationship among strain, crystallographic fabric, and seismic anisotropy. Earth and Planetary Science Letters 387, 157-168. doi:10.1016/j.eps1.2013.11. 009 
Hansen, L.N., Zimmermann, M.E., Dillman, A.M., Kohlstedt, D.L., 2012. Strain localization in olivine aggregates at high temperature: a laboratory comparison of constant-strain-rate and constant-stress boundary conditions. Earth and Planetary Science Letters 333-334, 134-145. doi:10.1016/j.epsl.2012.04.016.

Heilbronner, R., Tullis, J., 2006. Evolution of c axis pole figures and grain size during dynamic recrystallization: results from experimentally sheared quartzites. Journal of Geophysical Research 111. doi:10.1029/2005JB004194.

Herwegh, M., 2000. A new technique to automatically quantify microstructures of fine grained carbonate mylonites: two-step etching, combined with SEM imaging and image analysis. Journal of Structural Geology 22, 391-400. doi:10.1016/S0191-8141(99)00165-0.

Herwegh, M., de Bresser, J.H.P., ter Heege, J.H., 2005. Combining natural microstructures with composite flow laws: an improved approach for the extrapolation of lab data to nature. Journal of Structural Geology 27, 503-521. doi:10.1016/j.jsg.2004.10.010.

Herwegh, M., Handy, M.R., 1996. The evolution of high-temperature mylonitic microfabrics: evidence from simple shearing of a quartz analogue (norcamphor). Journal of Structural Geology 18, 689-710. doi:10.1016/S0191-8141(96)80033-2.

Herwegh, M., Handy, M.R., 1998. The origin of shape preferred orientations in mylonite: interferences from in-situ experiments on polycrystalline norcamphor. Journal of Structural Geology 20, 681-694. doi:10.1016/S0191-8141(98)00011-X.

Herwegh, M., Linckens, J., Ebert, A., Brodhag, S., 2011. The role of second phases for controlling microstructural evolution in polymineralic rocks: a review. Journal of Structural Geology 33, 1728-1750. doi:10.1016/j.jsg. 2011.08.011.

Herwegh, M., Pfiffner, O.A., 2005. Tectono-metamorphic evolution of a nappe stack: a case study of the Swiss Alps. Tectonophysics 404, 134-145. doi:10.1016/j.tecto.2005.05.002.

Herwegh, M., Poulet, T., Karrech, A., Regenauer-Lieb, K., 2014. From transient to steady state deformation and grain size: a thermodynamic approach using elasto-visco-plastic numerical modeling. Journal of Geophysical Research 119, 900-918. doi:10.1002/2013JB010701. 
Herwegh, M., Xiao, X., Evans, B., 2003. The effect of dissolved magnesium on diffusion creep in calcite. Earth and Planetary Science Letters 212, 457-470. doi:10.1016/S0012-821X(03) 00284-X.

Higgins, M.D., 2006. Quantitative Textural Measurements in Igneous and Metamorphic Petrology. Cambridge University Press.

Hirth, G., Tullis, J., 1992. Dislocation creep regimes in quartz aggregates. Journal of Structural Geology 14, 145-159. doi:10.1016/0191-8141(92)90053-Y.

Hobbs, B.E., Ord, A., 2012. Localised and chaotic folding: the role of axial plane structures. Philosophical Transactions of the Royal Society A 370, 1966-2009. doi:10.1098/rsta.2011.0426.

Hobbs, B.E., Ord, A., Regenauer-Lieb, K., 2011. The thermodynamics of deformed metamorphic rocks: a review. Journal of Structural Geology 33, 758-818. doi:10.1016/j.jsg.2011.01.013.

Hobbs, B.E., Regenauer-Lieb, K., Ord, A., 2007. Thermodynamics of folding in the middle to lower crust. Geology 35, 175-178. doi:10.1130/G23188A.

Hobbs, B.E., Regenauer-Lieb, K., Ord, A., 2008. Folding with thermal-mechanical feedback. Journal of Structural Geology 30, 1572-1592. doi:10.1016/j.jsg.2008.09.002.

Hobbs, B.E., Regenauer-Lieb, K., Ord, A., 2009. Folding with thermal mechanical feedback: a reply. Journal of Structural Geology 31, 752-755. doi:10.1016/j.jsg.2009.03.014.

Hudleston, P.J., Treagus, S.H., 2010. Information from folds: a review. Journal of Structural Geology 32, 2042-2071. doi:10.1016/j.jsg.2010.08.011.

Kidan, T.W., Cosgrove, J.W., 1996. The deformation of multilayers by layer normal compression: an experimental investigation. Journal of Structural Geology 18, 461-474. doi:10.1016/ 0191-8141(95)00099-Y.

Kilian, R., Heilbronner, R., Stünitz, H., 2011. Quartz microstructures and crystallographic preferred orientation: which shear sense do they indicate? Journal of Structural Geology 33, 1446-1466. doi:10.1016/j.jsg. 2011.08.005. 
Krabbendam, M., Urai, J.L., Vliet, L.J., 2003. Grain size stabilization by dispersed graphite in a high-grade quartz mylonite: an example from Naxos (Greece). Journal of Structural Geology 25, 855-866. doi:10.1016/S0191-8141(02)00086-X.

Mancktelow, N.S., 2001. Single-layer folds developed from initial random perturbations: the effects of probability distribution, fractal dimension, phase and amplitude. Geological Society of America Memoirs 193, 69-87. doi:10.1130/0-8137-1193-2.69.

Mancktelow, N.S., Abbassi, M.R., 1992. Single layer buckle folding in non-linear materials - 2. Comparison between theory and experiment. Journal of Structural Geology 14, 105-120. doi:10. 1016/0191-8141(92) 90148-P.

Mandal, N., R., D., Misra, S., Chakraborty, C., 2007. Use of boudinaged rigid objects as a strain gauge: insights from analogue and numerical models. Journal of Structural Geology 29, 759-773. doi:10.1016/j.jsg.2007.02.007.

Means, W., 1981. The concept of steady-state foliation. Tectonophysics 78, 179-199. doi:10.1016/ 0040-1951(81) 90013-5.

Mercier, J.C., Anderson, D.A., Carter, N.L., 1977. Stress in the lithosphere: inferences from steady-state flow of rocks. Pure and Applied Geophysics 115, 199-226. doi:10.1007/ 978-3-0348-5745-1_12.

Michibayashi, K., 1993. Syntectonic development of a strain-independent steady-state grain size during mylonitization. Tectonophysics 222, 151-164. doi:10.1016/0040-1951 (93)90046-M.

Needleman, A., Tvergaard, V., 1992. Analysis of plastic flow localization in metals. Applied Mechanics Reviews 45, 3-18. doi:10.1016/0191-8141(82)90028-1.

Neurath, C., Smith, R.B., 1982. The effect of material properties on growth rates of folding and boudinage: experiments with wax models. Journal of Structural Geology 4, 215-229. doi:10. 1016/0191-8141(82)90028-1.

Ord, A., Hobbs, B.E., 2011. Microfabrics as energy minimisers: Rotation recrystallisation as an example. Journal of Structural Geology 33, 220-243. doi:10.1016/j.jsg.2010.11.009. 
Ord, A., Hobbs, B.E., 2013. Localised folding in general deformations. Tectonophysics 587, 30-45. doi:10.1016/j.tecto.2012.09.020.

Passchier, C.W., Druguet, E., 2002. Numerical modelling of asymmetric boudinage. Journal of Structural Geology 24, 1789-1803. doi:10.1016/S0191-8141(01)00163-8.

Paterson, M.S., Weiss, I.E., 1968. Folding and boudinage of quartz-rich layers in experimentally deformed phyllite. Geological Society of America Bulletin 79, 795-812. doi:10.1130/ 0016-7606 (1968)79[795:FABOQL] 2.0.CO;2.

Peters, M., Veveakis, E., Poulet, T., Karrech, A., Herwegh, M., Regenauer-Lieb, K., 2015. Boudinage as a material instability of elasto-visco-plastic rocks. Journal of Structural Geology 78, 86-102. doi:10.1016/j.jsg.2015.06.005.

Pieri, M., Burlini, L., Kunze, K., Stretton, I., Olgaard, D., 2001. Rheological and microstructural evolution of Carrara marble with high shear strain: results from high temperature torsion experiments. Journal of Structural Geology 23, 1393-1413. doi:10.1016/S0191-8141 (01)00006-2.

Poulet, T., Veveakis, E., Herwegh, M., Buckingham, T., Regenauer-Lieb, K., 2014. Modeling episodic fluid-release events in the ductile carbonates of the Glarus thrust. Geophysical Research Letters 41, 7121-7128. doi:10.1002/2014GL061715.

Ramberg, H., 1955. Natural and experimental boudinage and pinch-and-swell structures. Journal of Geology 63, 512-526. doi:10.1086/626293.

Ramberg, H., Osgood, W.R., 1943. Description of stress and strain curves by three parameters. National Advisory Committee for Aeronautics (NACA) Technical Note 902.

Regenauer-Lieb, K., Hobbs, B.E., Ord, A., Gaede, O., Vernon, R.H., 2006. Deformation with coupled chemical diffusion. Physics of the Earth and Planetary Interiors 172, 43-54. doi:10. 1016/j.pepi.2008.08.013.

Regenauer-Lieb, K., Yuen, D.A., 2003. Modeling shear zones in geological and planetary sciences: solid- and fluid-thermal-mechanical approaches. Earth-Science Reviews 63, 295-349. doi:10. 1016/S0012-8252(03)00038-2. 
Regenauer-Lieb, K., Yuen, D.A., 2004. Positive feedback of interacting ductile faults from coupling of equation of state, rheology and thermal-mechanics. Physics of the Earth and Planetary Interiors 142, 113-135. doi:10.1016/j.pepi.2004.01.003.

Renner, J., Evans, B., 2002. Do calcite rocks obey the power-law creep equation? Geological Society London Special Publications 200,293-307. doi:10.1144/GSL.SP.2001.200.01.17.

Renner, J., Evans, B., Siddiqi, G., 2002. Dislocation creep of calcite. Journal of Geophysical Research 107, ECV 6-1-ECV 6-16. doi:10.1029/2001JB001680.

Rybacki, E., Evans, B., Janssen, C., Wirth, R., Dresen, G., 2013. Influence of stress, temperature, and strain on calcite twins constrained by deformation experiments. Tectonophysics $601,20-36$. doi:10.1016/j.tecto. 2013.04.021.

Rybacki, E., Morales, L.F.G., Naumann, M., Dresen, G., 2014. Strain localization during high temperature creep of marble: the effect of inclusions. Tectonophysics 634, 182-197. doi:10. $1016 / j$.tecto.2014.07.032.

Schmalholz, S.M., Fletcher, R.C., 2011. The exponential flow law applied to necking and folding of a ductile layer. Geophysical Journal International 184, 83-89. doi:10.1111/j.1365-246X.2010. 04846.x.

Schmalholz, S.M., Maeder, X., 2012. Pinch-and-swell structure and shear zones in viscoplastic layers. Journal of Structural Geology 37, 75-88. doi:10.1016/j.jsg.2012.01.026.

Schmalholz, S.M., Schmid, D.W., 2012. Folding in power-law viscous multi-layers. Philosophical Transactions of the Royal Society A 370, 1798-1826. doi:10.1098/rsta.2011.0421.

Schmalholz, S.M., Schmid, D.W., Fletcher, R.C., 2008. Evolution of pinch-and-swell structures in a power-law layer. Journal of Structural Geology 30, 649-663. doi:10.1016/j.jsg.2008.01.002.

Schmid, S.M., Paterson, M.S., Boland, J.N., 1980. High temperature flow and dynamic recrystallization in Carrara marble. Tectonophysics 65, 245-280. doi:10.1016/0040-1951(80)90077-3.

Shimizu, I., 2008. Theories and applicability of grain size piezometers: the role of dynamic recrystallization mechanisms. Journal of Structural Geology 30, 899-917. doi:10.1016/j.jsg.2008. 03.004 . 
Veveakis, E., Alevizos, S., Vardoulakis, I., 2010. Chemical reaction capping of thermal instabilities during shear of frictional faults. Journal of Mechanics and Physics of Solids 58, 2617-2640. doi:10.1016/j.jmps .2010.06.010.

White, S.H., Burrows, S.E., Carreras, J., Shaw, N.D., Humphreys, F.J., 1980. On mylonites in ductile shear zones. Journal of Structural Geology 2, 175-187. doi:10.1016/0191-8141(80) 90048-6.

Wightman, R.H., Prior, D.J., Little, T.A., 2006. Quartz veins deformed by diffusion creep accommodated grain boundary sliding during a transient, high strain-rate event in the Southern Alps, New Zealand. Journal of Structural Geology 28, 902-918. doi:10.1016/j.jsg.2006.02.008.

Yuen, D.A., Fleitout, L., Schubert, G., 1978. Shear deformation zones along major transform faults and subducting slabs. Geophysical Journal International 54, 93-119. doi:10.1111/j.1365-246X . 1978.tb06758.x.

Yuen, D.A., Schubert, G., 1979. On the stability of frictionally heated shear flows in the asthenosphere. Geophysical Journal International 57, 189-208. doi:10.1111/j.1365-246X.1979. tb03780.x. 

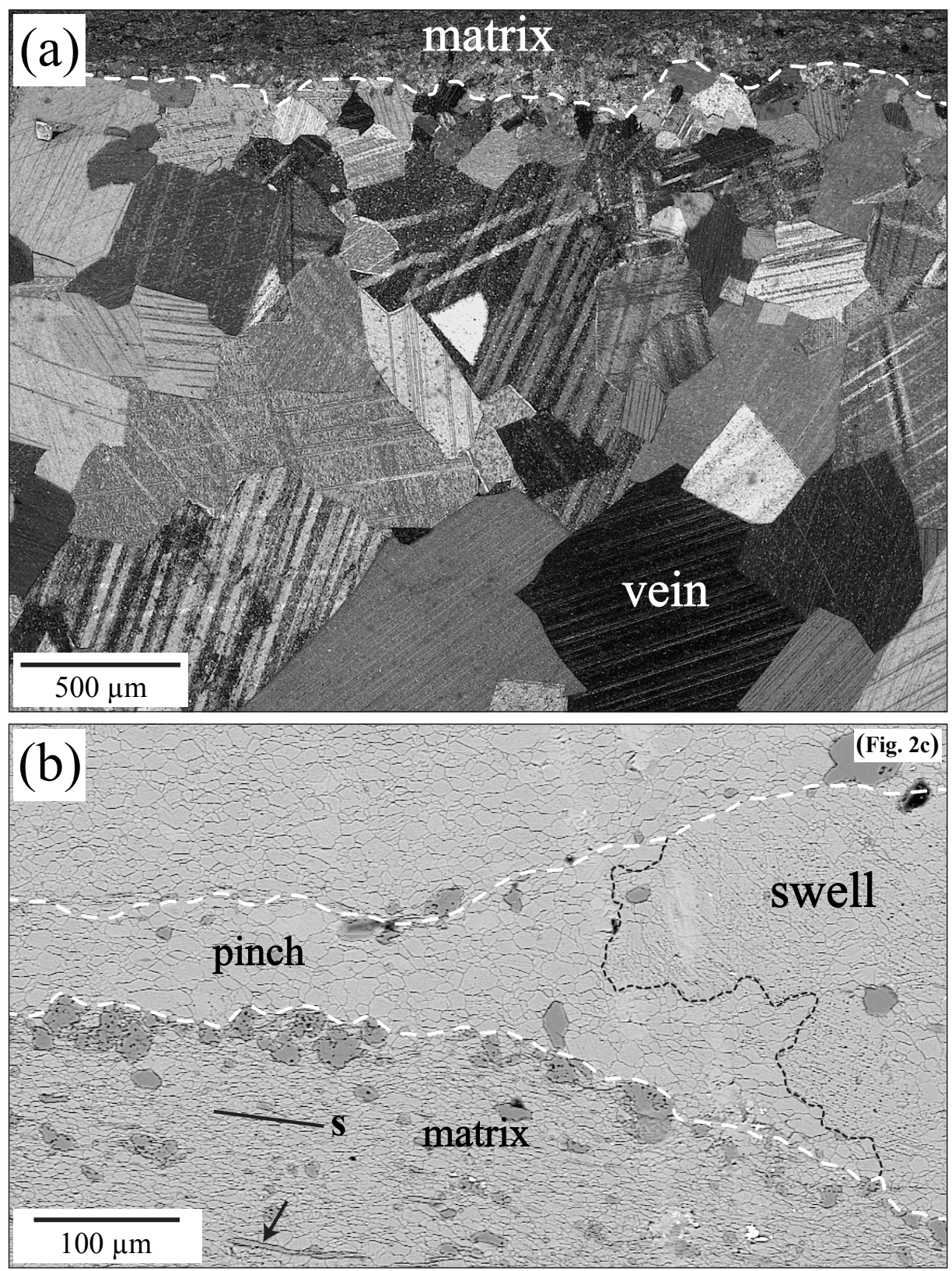

Fig. 1: Characteristic end-member structures of monomineralic veins from the study area (Doldenhorn nappe, Helvetic Alps), studied in (a) an undeformed, coarse-grained calcite vein and (b) a deformed calcite vein forming a pinch-and-swell structure. (a) Cross-polarized micrograph of undeformed original calcite grains, interpreted as the precursor structure of boudinaged veins. (b) Electron-backscatter image of a pinch-and-swell structure. The swells appear as heavily-twinned, original calcite clasts. The boudinaged vein is embedded into a fine-grained polymineralic matrix. The grain sizes of newly formed grains severely decrease inside the pinch (see also Fig. 2c). Arrow indicates chlorite grain, defining the foliation (S). White line: layer - matrix interface, black line: boundary between host calcite in swell and the fine-grained calcite in pinch. 

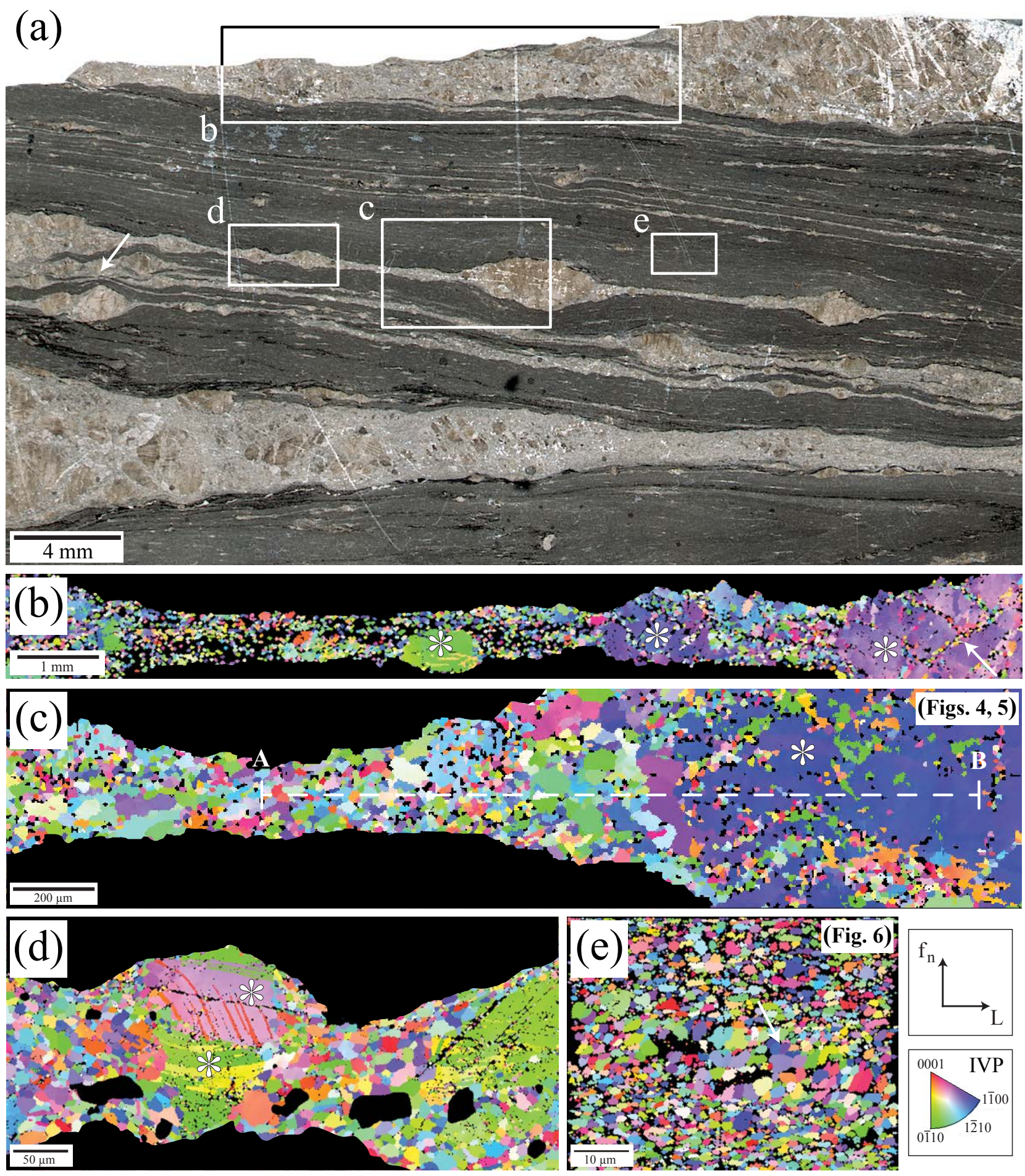

Fig. 2: Overview micrograph (a) and EBSD grain orientation maps (inverse pole figure color coding, reference direction $=\mathrm{Z}$ ) of boudinaged calcite veins (b-d), embedded in an ultramylonitic matrix (e). (a) Thin section scan (plane-polarized light) with sampling sites for EBSD mappings. (b) Coarse orientation map of a boudinaged vein. Arrow indicates preferred dynamic recrystallization along twin planes of host grains in the swell. (c) Close-up of a characteristic neck showing a clear grain size gradient from swell to pinch. Dashed line (A-B) indicates profile for misorientation angle measurements (see Fig. 4). (d) Twinned host single crystals define the swell with recrystallized grains in the pinches. (e) Grain orientation map of the host rock matrix (for the misorientation distribution see Fig. 5); arrow: correlated aggregates. Asterisks indicate host calcite grains, which were analyzed with EBSD (Fig. 3). $\mathrm{f}_{n}$ : foliation normal, L: lineation. 


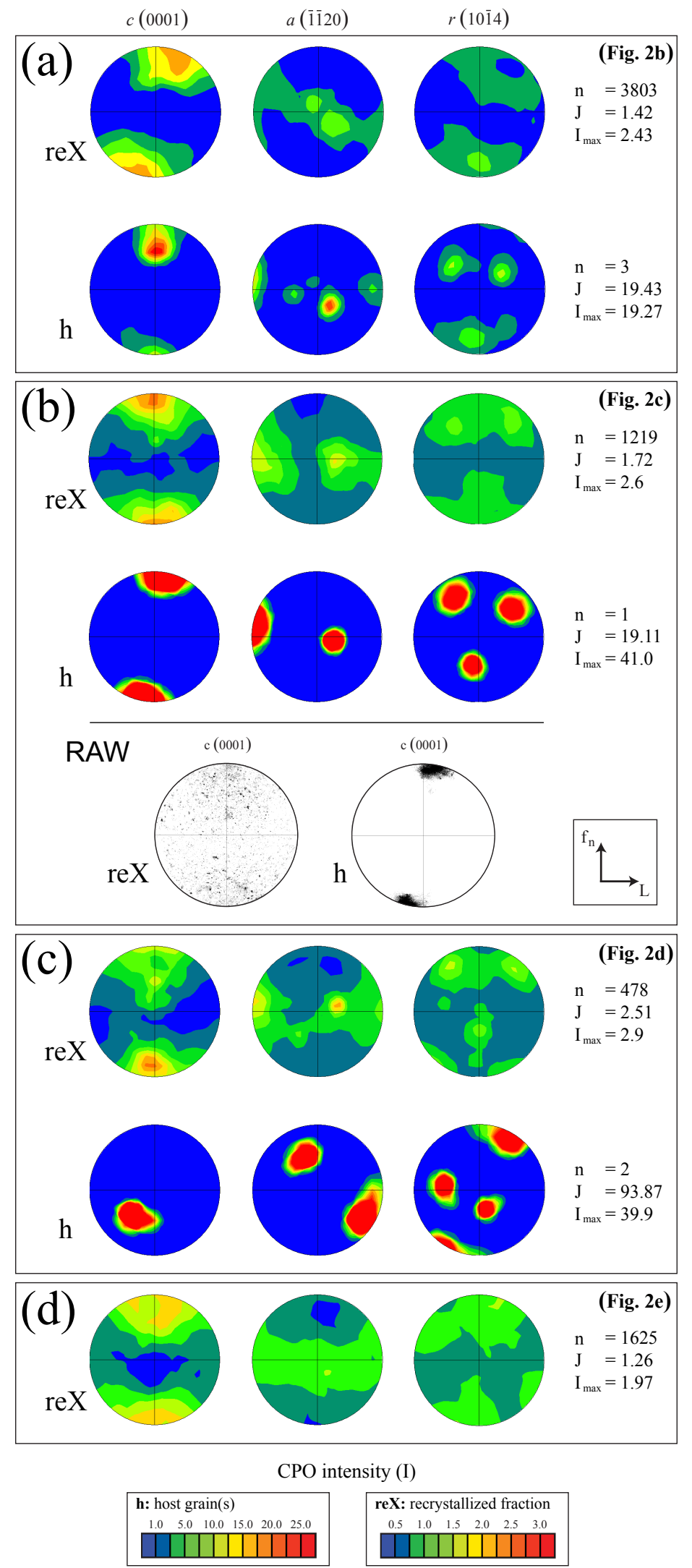

Fig. 3: Pole figure diagrams of fine-grained recrystallized fractions (reX) and host calcite grains (h) from pinch-and-swell structures, calculated from EBSD orientation mappings. Shown are the characteristic basal c (0001), prismatic $a(\overline{11} 20)$ and rhomb $r(10 \overline{1} 4)$ planes. Plots per point: upper hemisphere, equal-area projection, linear contouring. Corresponding grain orientation maps are given in Figure 2b-e. See text for the interpretation of the microtextures. $\mathrm{f}_{n}$ : foliation normal, $\mathrm{I}_{\max }$ : maximum intensity (note the different legends for fine fractions and host grains), J: fabric strength factor, L: lineation, n: number of measured grains. 

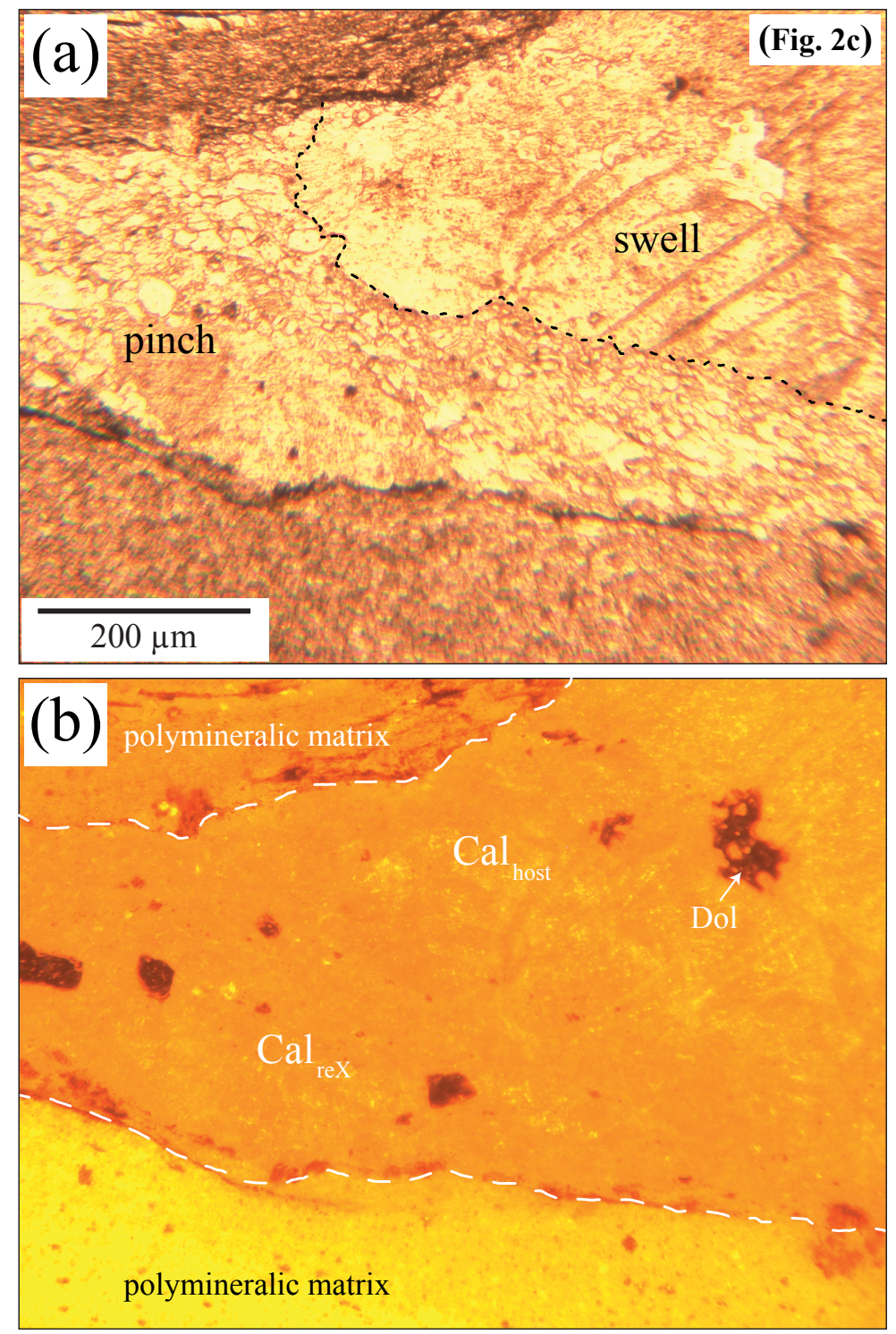

Fig. 4: Study of the chemical composition of a characteristic pinch-and-swell structure. (a) Plane-polarized micrograph of a neck shown in Figure 2c. Dashed line: boundary between host calcite - recrystallized calcite. (b) Cathodoluminescence image (20kV, 30s lightning) revealing no noticeable difference in calcite chemistry between the swell and the pinch. Abbreviations: Cal host: host calcite clast, $\mathrm{Cal}_{r e X}$ : fine-grained, recrystallized calcite grains, Dol: dolomite. Dashed line: layer - matrix interface. 
A pinch

(iii)

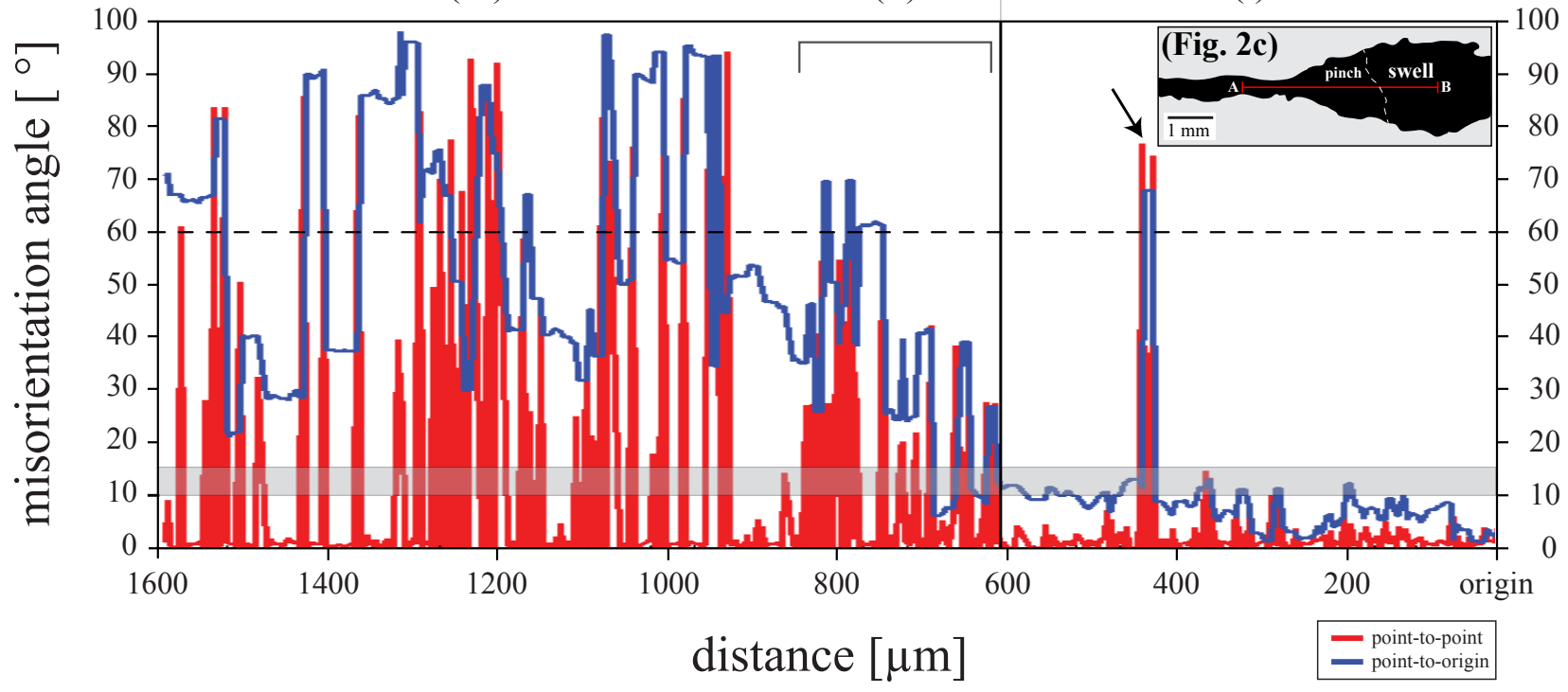

Fig. 5: Misorientation angle profile, obtained from Euler angle measurements, across a characteristic pinch-and-swell structure (profile line A-B defined in Fig. 2c). The profile reveals clear differences in (i) the swell with a change from low- to high-angle boundaries, (ii) the pinch showing progressive formation of high-angle boundaries to (iii) ultimately random orientations. Horizontal dashed line: potential orientations following twin orientations, occurring at $60^{\circ}$ to $<\mathrm{c}>$; grey shaded area $\left(10-15^{\circ}\right)$ : transition low- to high-angle grain boundaries. The uncorrelated peak (arrow) is due to an undetected dolomite grain in the orientation map. Blue line: point-to-origin misorientation, red line: point-to-point misorientation. The origin is defined in Figure 2c (point B). 

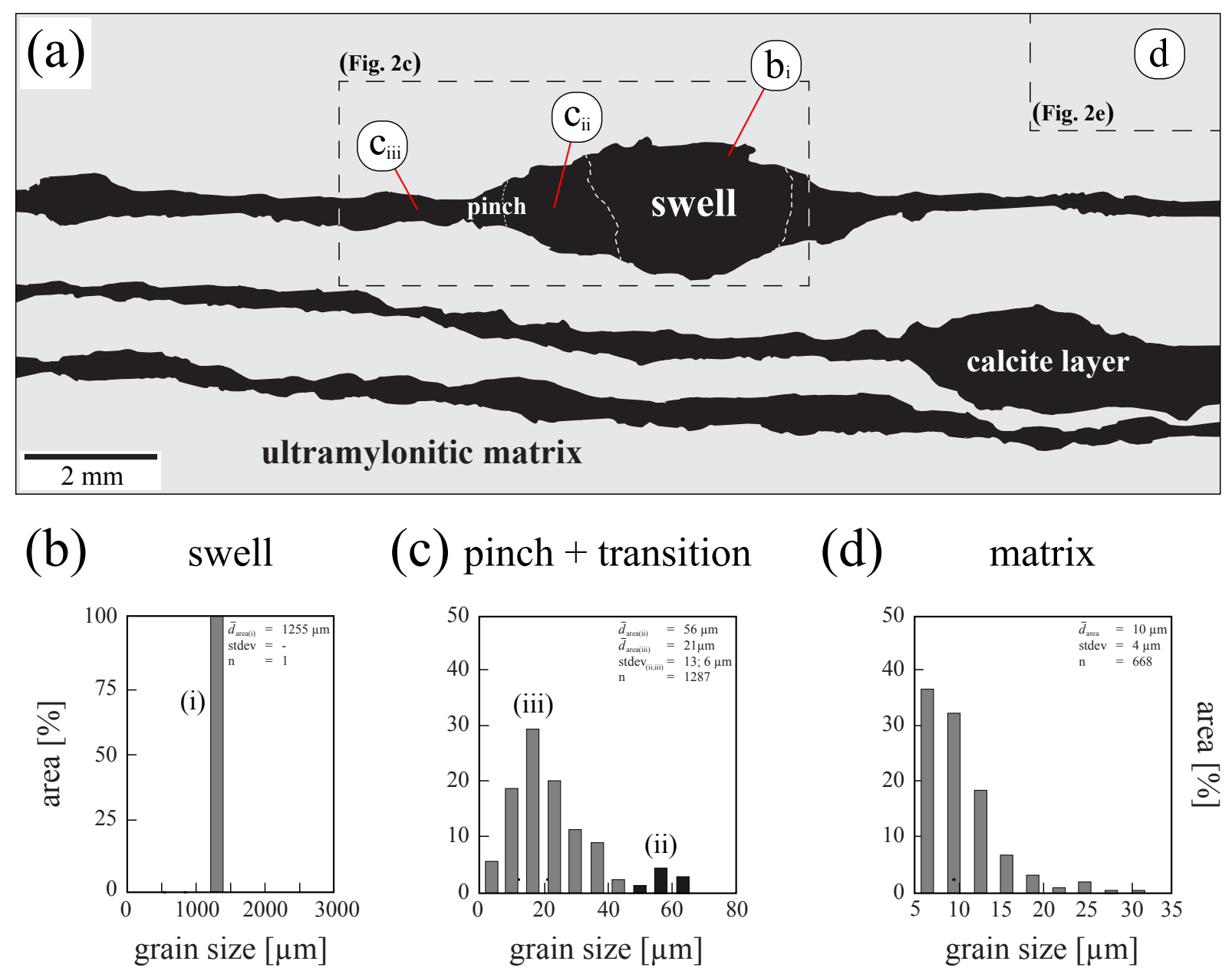

Fig. 6: Study of grain size variations across a characteristic pinch-and-swell structure (see Fig. 2c) and the surrounding matrix, in (a) overview sketch and (b) grain size distributions of the coarse-grained swell (i), (c) fine-grained transition (ii) and the most-extended part of the pinch (iii). A bimodal grain size distribution defines the general grain size gradient in the pinch (Fig. 2c). (d) Calcite grains measured in the matrix (Fig. 2e). We have added labels according to the misorientation angle profile of Figure $5 . \bar{d}_{\text {area }}$ : area-weighted mean grain size in $[\mu \mathrm{m}], \mathrm{n}$ : number of measured grains, stdev: standard deviation on $\bar{d}_{\text {area }}$. 


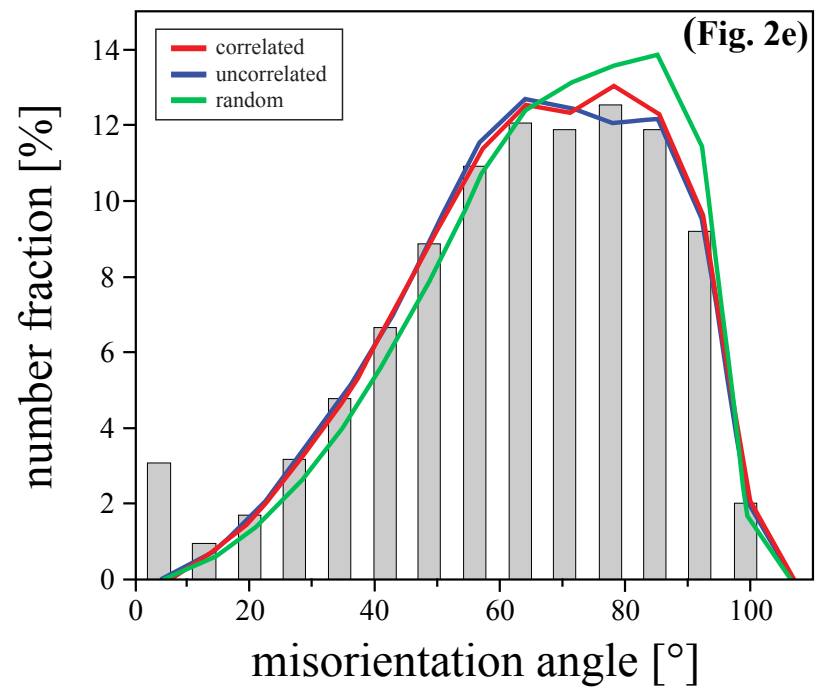

Fig. 7: Bulk misorientation angle distribution of the fine-grained ultramylonitic matrix (see Fig. 2e) in comparison to computed correlated (red), uncorrelated (blue) and random (green) misorientation distributions. 
(a)

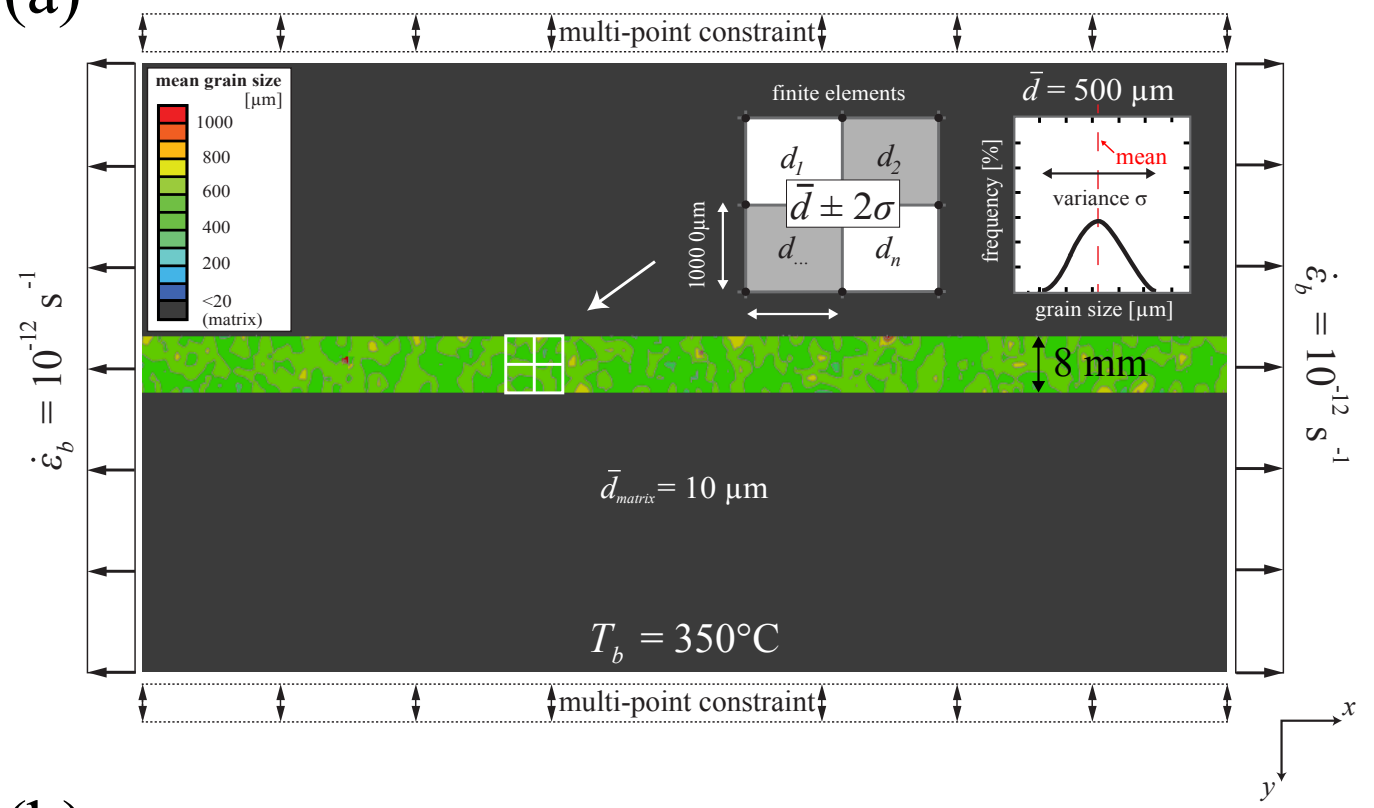

(b)

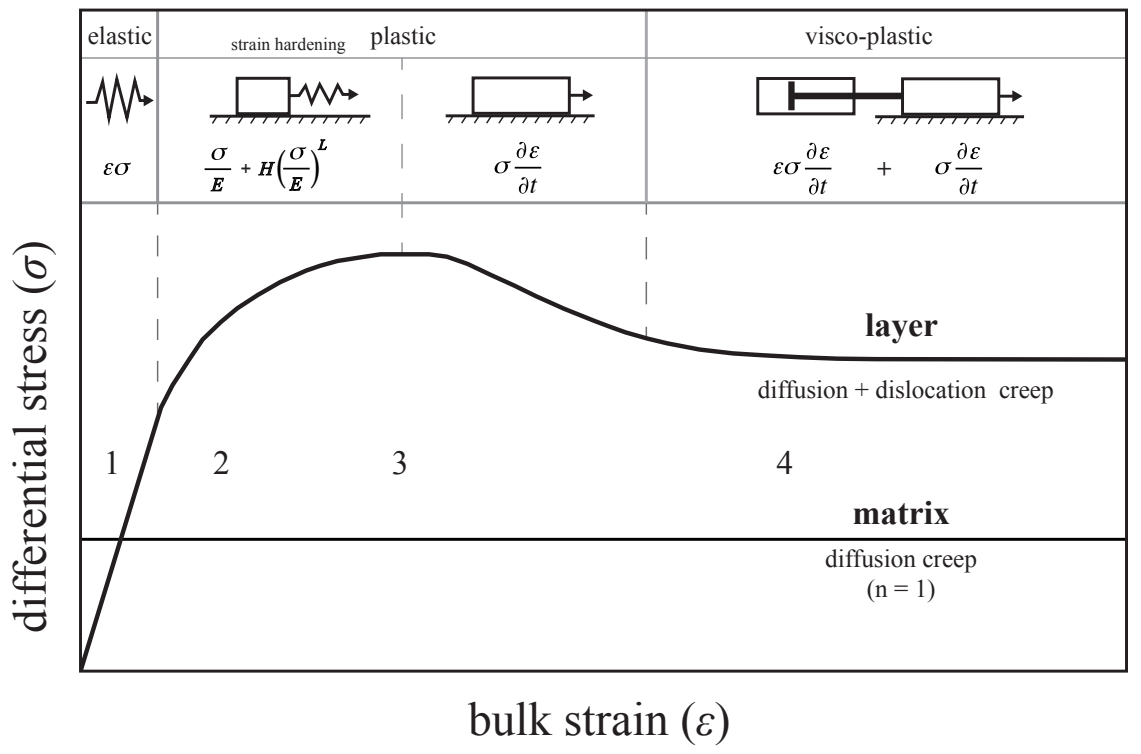

Fig. 8: Implementation of the microstructure into a finite element framework, including the deformation behavior of the aggregates (for further details see Herwegh et al., 2014). (a) Principal mechanical sequence of (1) linear-elastic behavior for small strains, (2) followed by strain hardening (Ramberg and Osgood, 1943), (3) strain softening via dislocation creep and (4) finally (steady-state) viscous creep, expressed by the balance between diffusion and dislocation creep in the layer (thick line). We assume a linear matrix response by diffusion creep (thin line). (b) Sketch of the numerical pure shear box, modified from Peters et al. (2015). Box dimensions: $240 \times 120$ finite elements, each of size $1000 \times 1000 \mu \mathrm{m}$. The layer - box height aspect ratio is 0.07 . Individual mean grain sizes $\left(d_{i}\right)$ are randomly distributed over the layer and averaged by $\bar{d}$, given a variance of $2 \sigma$. The boundary conditions $\left(\dot{\epsilon}_{0}, T_{b}\right)$ are chosen to represent the natural deformation conditions for the field area. The left- and right-hand side model boundaries are periodic in displacement in $x$-direction. The upper and lower box boundaries admit zero displacement in the $y$-direction (multi-point constraint) and are frictionless sliding in the $x$-direction. 
(a)

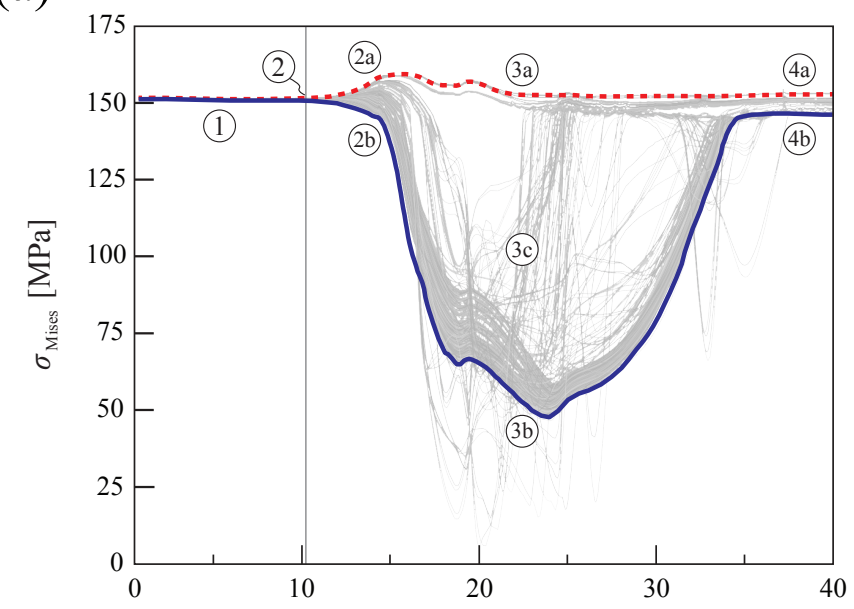

(b)

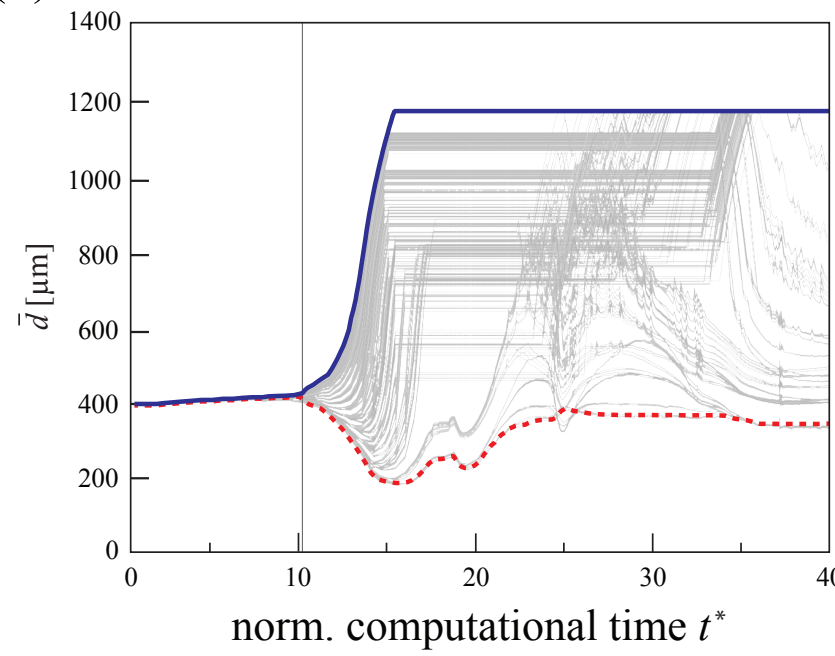

(c)

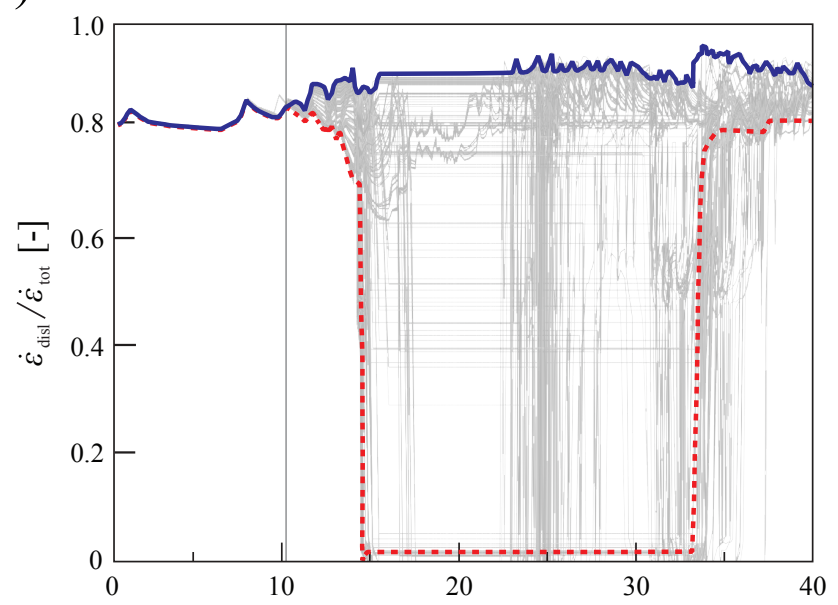

(d)

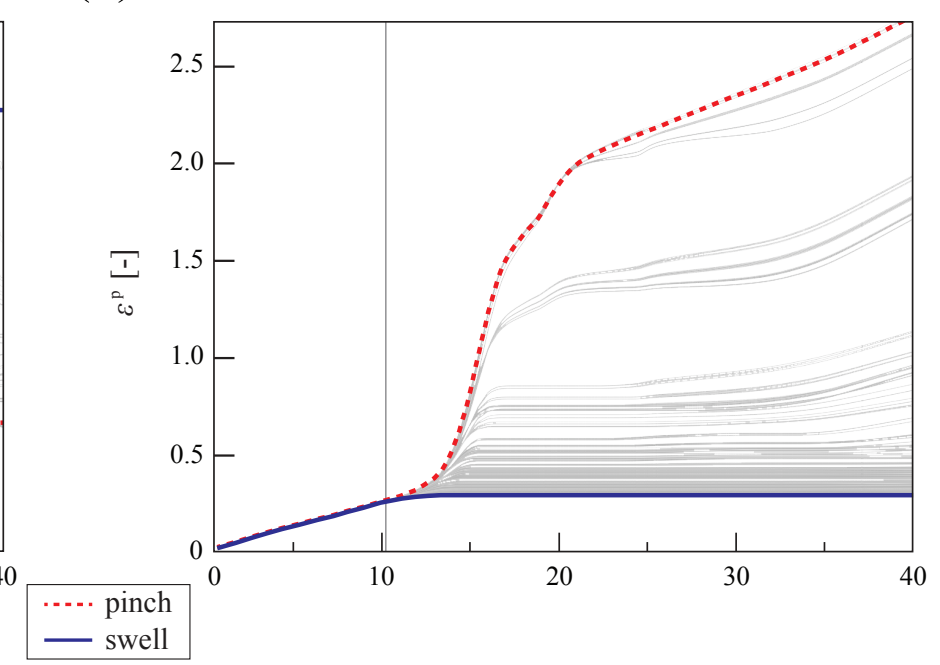

Fig. 9: Numerically simulated rheological data for one characteristic pinch-and-swell structure in the visco-plastic regime against the normalized computational time $\left(t^{*}=t \times \dot{\epsilon}_{0}\right)$ : (a) von Mises stress [MPa], (b) mean grain size [ $\left.\mu \mathrm{m}\right]$, (c) contribution of dislocation creep to the total creep rate and (d) equivalent plastic strain. The sequence uncovers the existence of multiple steady states with respect to time (1) - (4) and location, i.e. a locally stable pinch (4a) and swell (4b). (2) The onset of localization clearly occurs from homogeneous state (vertical line). The transient regime (3c) is expressed by the gradient between the developing end-members (3a) - (3b). Boundary conditions: $\dot{\epsilon}_{0}=10^{-12} \mathrm{~s}^{-1} ; T_{b}=350^{\circ} \mathrm{C}$. Highlighted are the end-member data for a swell (blue line) and a pinch (red line). Underlain are the raw data across the entire pinch, revealing a gradient of increasing strain from swell to pinch. 


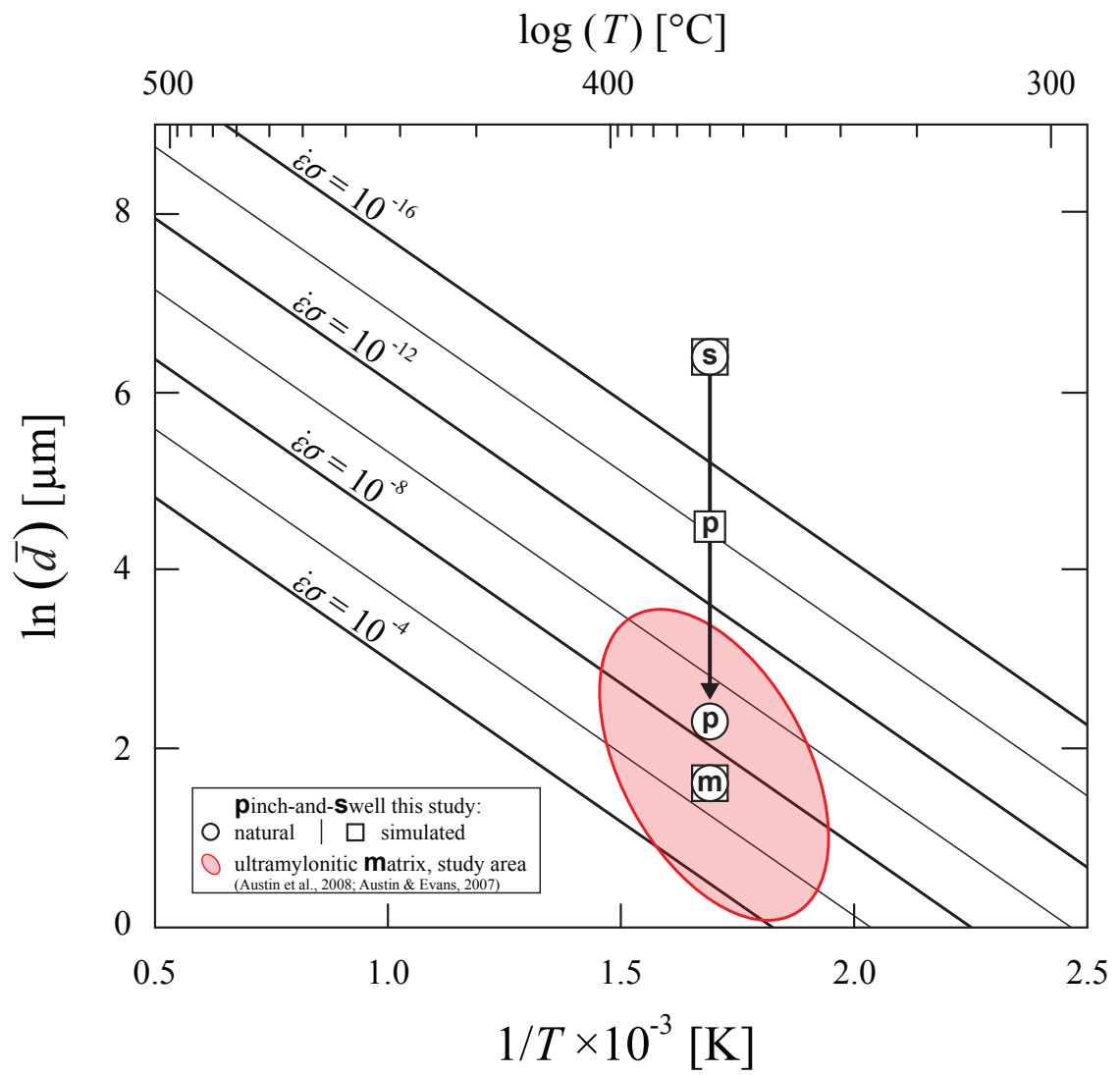

Fig. 10: Comparison of the measured (Fig. 6c) and numerically simulated (Fig. 9b) mean grain sizes $(\bar{d})$ for one pinch-and-swell structure, embedded into the deformation conditions $(T)$. The amount of plastic work (contour lines) is calculated through the Paleowattmeter relationship for dominant dislocation creep of calcite. Arrow indicates the strain gradient, expressed by grain size reduction from swell (s) to pinch (p). Red area highlights previously published $d-T$ data of ultramylonites from the Helvetic Alps (Austin et al., 2008; Ebert et al., 2007a). Area-weighted mean recrystallized grain sizes were recalculated to line-intercept grain sizes (Berger et al., 2011). Graph modified from figure 4 of Austin and Evans (2007). m: matrix grain size. 
Tab. 1: Thermo-mechanical properties of calcite for pinch-and-swell finite element simulations.

\begin{tabular}{|c|c|c|c|c|}
\hline & Quantity & Unit & Layer & Matrix \\
\hline$\alpha$ & Thermal expansion coef. & $1 / \mathrm{K}$ & \multicolumn{2}{|c|}{$7.6 \times 10^{-6}$} \\
\hline$c_{p}$ & Specific heat & $\mathrm{J} / \mathrm{K} / \mathrm{kg}$ & \multicolumn{2}{|c|}{787} \\
\hline$E$ & Young's modulus & $\mathrm{Pa}$ & $7.3 \times 10^{9}$ & $7.3 \times 10^{8}$ \\
\hline$H$ & Hardening coef. & - & \multicolumn{2}{|c|}{4} \\
\hline$\kappa$ & Thermal conductivity & $\mathrm{W} / \mathrm{m} / \mathrm{kg}$ & \multicolumn{2}{|c|}{1.4} \\
\hline$L$ & Hardening exponent & - & \multicolumn{2}{|c|}{3} \\
\hline$\lambda$ & Energy stored in the microstr. & - & \multicolumn{2}{|c|}{0.1} \\
\hline$\rho$ & Mass density & $\mathrm{kg} / \mathrm{m}^{3}$ & \multicolumn{2}{|c|}{2710} \\
\hline$\tau_{\text {yield }}$ & Elastic yield stress & $\mathrm{Pa}$ & $2.5 \times 10^{7}$ & $5.0 \times 10^{6}$ \\
\hline$\nu$ & Poisson's ratio & - & \multicolumn{2}{|c|}{0.285} \\
\hline
\end{tabular}

